\title{
Patient-centered care and its effect on outcomes in the treatment of asthma
}

\author{
This article was published in the following Dove Press journal: \\ Patient Related Outcome Measures \\ 10 June 2011 \\ Number of times this article has been viewed
}

\author{
Nashmia Qamar',* \\ Andrea A Pappalardo², \\ Vineet $M$ Arora $^{3}$ \\ Valerie G Press ${ }^{4}$ \\ 'Pediatric Residency Program, \\ University of Chicago Medical \\ Center, Chicago, IL, USA; ${ }^{2}$ Internal \\ Medicine-Pediatric Residency \\ Program, University of Chicago \\ Medical Center, Chicago, IL, USA; \\ ${ }^{3}$ Section of General Internal Medicine, \\ Department of Medicine, University \\ of Chicago Medical Center, Chicago, \\ IL, USA; ${ }^{4}$ Section of Hospital Medicine, \\ Department of Medicine, University \\ of Chicago Medical Center, Chicago, \\ IL, USA \\ *Drs Qamar and Pappalardo \\ contributed equally to this paper
}

Correspondence: Valerie G Press Section of Hospital Medicine, Department of Medicine, University of Chicago Medical Center, 584I S Maryland Ave, MC 5000 W305, Chicago, IL 60637, USA

$\mathrm{Tel}+\mathrm{I} 7737025170$

Fax +I 7737957398

Emailvpress@medicine.bsd.uchicago.edu
Abstract: Patient-centered care may be pivotal in improving health outcomes for patients with asthma. In addition to increased attention in both research and clinical forums, recent legislation also highlights the importance of patient-centered outcomes research in the Patient Protection and Affordable Care Act. However, whether patient-centered care has been shown to improve outcomes for this population is unclear. To answer this question, we performed a systematic review of the literature that aimed to define current patient-focused management issues, characterize important patient-defined outcomes in asthma control, and identify current and emerging treatments related to patient outcomes and perspectives. We used a parallel search strategy via Medline ${ }^{\circledR}$, Cochrane Central Register of Controlled Trials, CINAHL ${ }^{\circledR}$ (Cumulative Index to Nursing and Allied Health Literature), and PsycINFO ${ }^{\circledR}$, complemented with a reference review of key articles that resulted in a total of 133 articles; 58 were interventions that evaluated the effect on patient-centered outcomes, and 75 were descriptive studies. The majority of intervention studies demonstrated improved patient outcomes (44; "positive" results); none showed true harm ( 0 ; "negative"); and the remainder were equivocal (14; "neutral"). Key themes emerged relating to patients' desires for asthma knowledge, preferences for tailored management plans, and simplification of treatment regimens. We also found discordance between physicians and patients regarding patients' needs, beliefs, and expectations about asthma. Although some studies show promise regarding the benefits of patient-focused care, these methods require additional study on feasibility and strategies for implementation in real world settings. Further, it is imperative that future studies must be, themselves, patientcentered (eg, pragmatic comparative effectiveness studies) and applicable to a variety of patient populations and settings. Despite the need for further research, enough evidence exists that supports incorporating a patient-centered approach to asthma management, in order to achieve improved outcomes and patient health.

Keywords: patient-focused, patient outcomes, quality of life

\section{Introduction}

Asthma is a complex disease entity. Treatment and research efforts often focus on understanding its immunologic and pathophysiologic processes. However, managing asthma presents clinicians with therapeutic challenges beyond this microbiologic level, and involves collaboration among clinicians and patients. In 2006, Irwin and Richardson, reviewed the benefits and barriers to the implementation of patient-centered care and defined patient-focused care as merging patient education, self-care and evidence-based models of medical practice. They further stated the need to introduce more equality into the physician/patient relationship and to focus as vigorously on patients' knowledge, understanding and participation as we do 
on understanding the disease itself. ${ }^{1,2}$ They identified four intervention areas: communication, partnerships, health promotion, and physical care, achieved using the "three Cs: communication, continuity of care, and concordance" ${ }^{\prime 1}$ all of which incorporate a complex interplay of psychological and behavioral characteristics. ${ }^{1-9}$

Patient-centered care has been demonstrated to improve care for patients with chronic disease such as diabetes and even chronic obstructive pulmonary disease (COPD). Bodenheimer et al discusses the chronic care model's effect on chronic disease management using diabetes as an example in his 2002 meta-analysis of 39 interventional studies. He found that 32 of the 39 studies found at least one outcome or process measure improved and two-thirds of the articles additionally showed a reduction in overall costs. ${ }^{10}$ The chronic care model embraces patient-centered care through the use of a comprehensive patient-centered medical home that considers the many barriers to access and successful execution of a care plan. In 2007, the American Academy of Family Physicians (AAFP), American College of Physicians (ACP), American Academy of Pediatrics (AAP), and Alpha Omega Alpha (AOA) all prioritized this concept of a patient-centered medical home. ${ }^{11}$ In addition, many studies have reviewed specific approaches for intervention in diabetes self-management via educational programs. ${ }^{12}$ For COPD, Adams et al performed a systematic review of the chronic care model and found that utilizing two components of this approach helped reduce hospitalizations and emergency department (ED) visits. ${ }^{13}$

Although asthma was represented to a smaller extent in some of these studies, ${ }^{10}$ the question remains whether the patient-centered care concept, which provides a major component of the chronic care model, actually translates to improvement in asthma outcomes. Research to this point does not appear to sufficiently address patient-centered management therapies and techniques, nor are the research designs themselves adequately patient-focused. The increased attention to patient-centered care comes not only from clinicians, but also researchers and even in legislative efforts, as patient-centered outcomes are recognized as a priority in the Patient Protection and Affordable Care Act 2010. ${ }^{14}$ To obtain increased resources for clinical, research, and policy efforts to improve patient-centered care for patients with asthma, it is imperative to critically review the existing literature for this patient population to determine what, if any, patient-focused outcomes are improved utilizing this approach. Thus, the objective of our systematic review is to assess the patient-centered approach to the treatment of asthma and to determine whether patient-focused care improves asthma outcomes.

\section{Material and methods}

We focused our review using the Medline ${ }^{\circledR}$ search strategy as our primary search engine and then complemented these findings with parallel searches as detailed below. In addition, we limited our review to adults and adolescents, as the care of children largely incorporates the beliefs and actions of the adult caregiver. The Medline search (1950-2010) included MeSH (Medical Subject Headings) terms in conjunction with "asthma": "patient perspectives", "patient satisfaction", "patient perception/patient goals", "patient centered care", "quality of life", "outcomes", "management" and "selfmanagement", limited to "human studies" and "English language", and resulted in 2051 articles. Three independent readers (NQ, AP, VP) performed title and abstract reviews based on exclusion criteria (caregivers, children, asthma camps, asthma action plans, validations of questionnaires, editorials, studies involving small groups lacking easy generalizability, diseases other than asthma) and inclusion criteria (asthma, patient-centered care, adults, adolescents, English language). We also searched $\mathrm{CINHAL}^{\circledR}$ (Cumulative Index to Nursing and Allied Health Literature), PsycINFO ${ }^{\circledR}$, and The Cochrane Central Register of Controlled Trials (2007-2011) databases, utilizing a parallel search strategy and a reference review of key included articles. We first performed a title and abstract review meeting key criteria, resulting in 945 total studies to be retrieved and assessed for final inclusion.

Studies included under these criteria were further subdivided to determine whether the study was primarily descriptive or intervention based. For those that were interventional studies, we extracted them to assess whether patient-focused results improved ("positive"), were equivocal ("neutral"), or did not improve ("negative"). For articles that included a combination of positive, neutral, and negative results, we characterized the article based on their stated primary outcome. If the primary outcome was unclear (as was the case in three articles), we brought them to a committee review and made a group decision on how the article in question should be classified. In the following sections we present the results of this literature review.

\section{Results}

Ultimately, 133 studies met all inclusion and no exclusion criteria. Over half were descriptive (75), and the remaining studies were interventional (58:44 positive, 14 neutral, 0 negative) (Table 1 ). The findings from our review are 
described below and are structured around the themes that arose. We provide a summary of these findings in relationship to these themes in Figure 1.

\section{Patient-focused management issues in the treatment of asthma}

The first major theme involves issues with implementation of patient-focused care. Most of the studies that focused on this theme were descriptive (6), though the one intervention study favored patient-centered care.

\section{Evidence and outcomes for patient-focused care of asthma}

There is some evidence to support that providers employing the patient-centered approach in the management of asthma improve patients' perspectives of asthma control. Patient preferences for clinical encounters in disease states other than asthma were ascertained from patients through a questionnaire distributed in a pre-operative waiting room, which yielded an impressive $95 \%$ return rate, in a study designed by Little et al. ${ }^{15}$ They discovered key aspects to care, including communication, partnership, and health promotion. Similarly, Flocke ${ }^{16}$ identified four approaches to physician consultation interactions in his study in a primary-care practice in Northeastern Ohio: person-focused, bio-psychosocial, biomedical, and high physician control, and compared them with patient-evaluated quality attributes. With respect to patients with asthma, the patient-centered approach has been found to not only be something of interest to patients, but something patients are willing to pay for. Barner et al ${ }^{8}$ looked into how much time and money patients are willing to put into an educational program to have their asthma control improved. They found that when patients were presented with a scenario of an 8-week asthma educational program, they were willing to spend a mean of 5.8 hours a week and $\$ 29.50$ or more if they perceived a self-management program to be beneficial. Further, the patient-centered approach has been found to improve patient satisfaction, symptom burden, and outcomes even for difficult-to-treat patients and adolescents. ${ }^{1,17}$ Villanueva et a ${ }^{17}$ highlighted an intervention using a comprehensive asthma center and found that although initial costs increased, the long-term health benefits and cost savings made it worth it.

\section{Barriers to patient-centered approaches}

When studied, patients can provide insight into barriers interfering with the completion of their treatment plan. These barriers include discordance between patients and physicians on patients' needs versus physicians' underestimation of the patient's desire for disease-specific knowledge. ${ }^{3,18}$ For instance, among patients with pulmonary diseases, information needs are not adequately met by physicians in the form of verbal and written information regarding diagnostics, cause of illness, prognosis, and use of long-term medication. ${ }^{19}$ White and Sander ${ }^{20}$ confirm this concept when looking at asthma severity, treatment, and medication side-effects. The authors found that although a majority (73\%) of respondents mentioned side-effects of beta-agonists to their physicians, most were told this was to be expected. Because of this, a third (33\%) of adults reduced their bronchodilator dose or frequency to avoid side-effects, and a quarter (24\%) skipped doses without physician instruction.

Poor patient-clinician communication is independently associated with poor adherence. ${ }^{21}$ Barry et al studied "patient agendas", an approach that allows for patients to express their feelings and opinions ${ }^{22}$ and discovered unvoiced concerns regarding psychosocial stressors and omission of key biomedical information that resulted in unwanted prescriptions and nonadherence. Newcomb et $\mathrm{a}^{23}$ identified patient barriers to successful asthma management, including a lack of communication from physicians in regards to daily asthma management (31\%) and home management of asthma (24\%). However, one-third of clinicians report they assist patients in decision-making (30\%) and tailor medication schedules around patient routines (33\%). Physicians do not recognize this breakdown in communication, compounding the problem further. ${ }^{24}$ Despite this, patients with asthma seek continuityof-care and guidance from their physicians, more so than other groups of patients..$^{25}$

Adolescents' views of specific barriers differ compared to adults. Adolescence represents a transition to adulthood, ${ }^{26}$ and asthma complicates this transition. ${ }^{27,28}$ Psychosocial factors such as anxiety, depression, risk-taking behaviors, and family dysfunction, can complicate asthma control. ${ }^{29}$ In a cross-sectional study by Rhee, adolescents with asthma cited barriers such as negativity toward providers and medication regimens, cognitive difficulties, peer/family influences, and denial. ${ }^{6}$ Those with increased knowledge and self-efficacy experience less barriers, suggesting that psychosocial factors may be even stronger predictors of self-management obstacles in adolescents versus adults.

\section{Characterizing specific and important outcomes in patients' perspectives of asthma control}

As seen previously, patients seek an active role and identify barriers to their care. The second theme that 


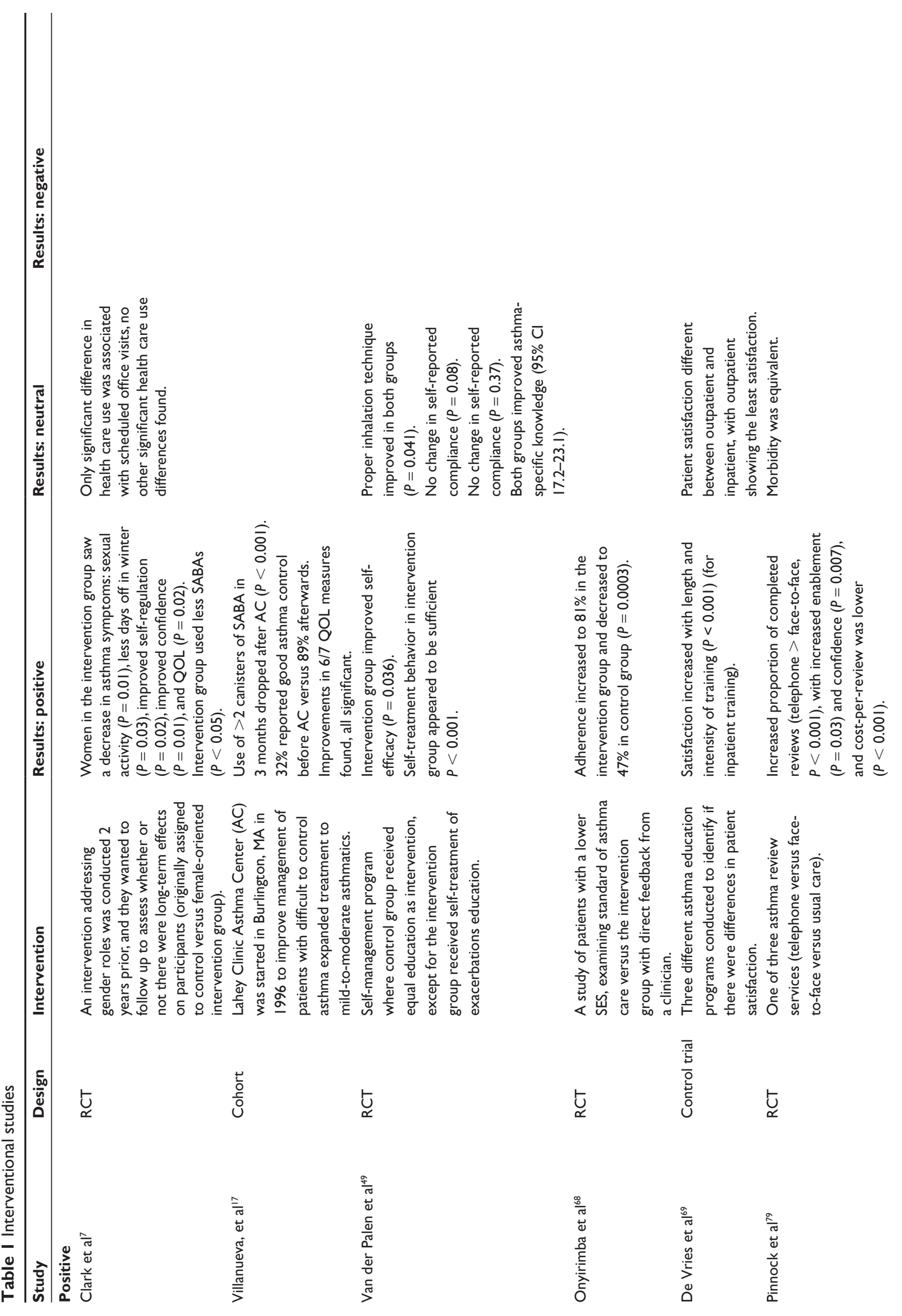



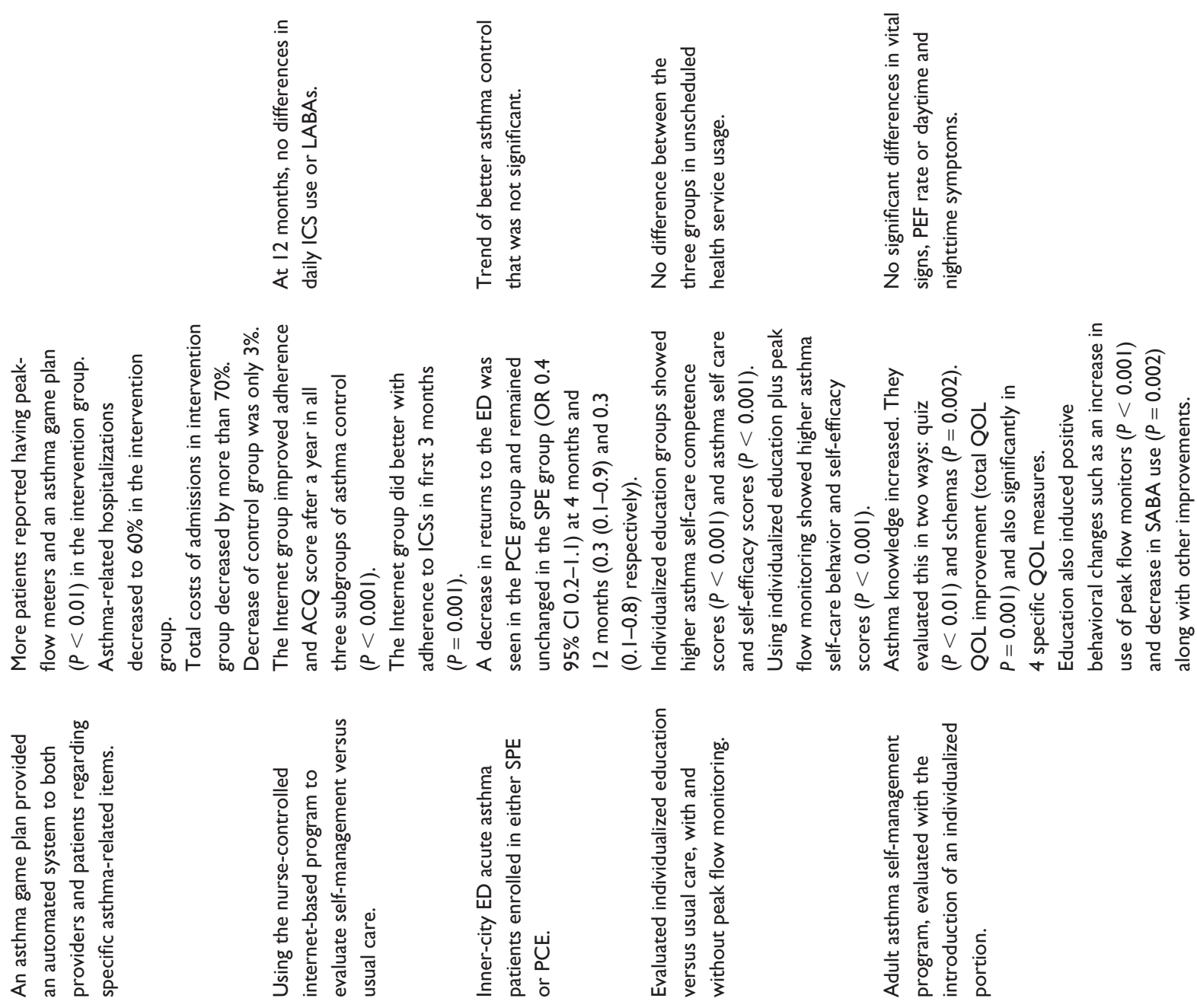

$\stackrel{\leftarrow}{\longleftarrow}$

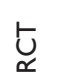

$\underset{\simeq}{\longleftarrow}$

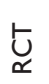

$\frac{}{\frac{1}{0}}$
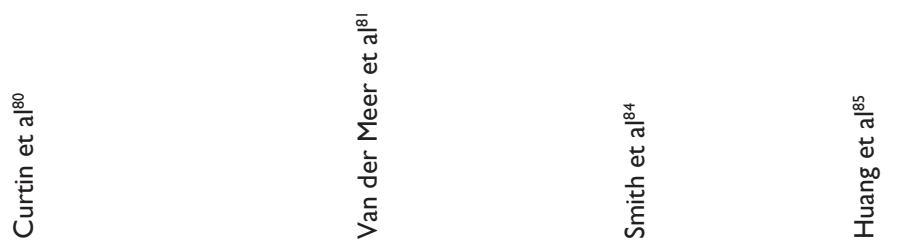

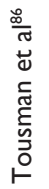




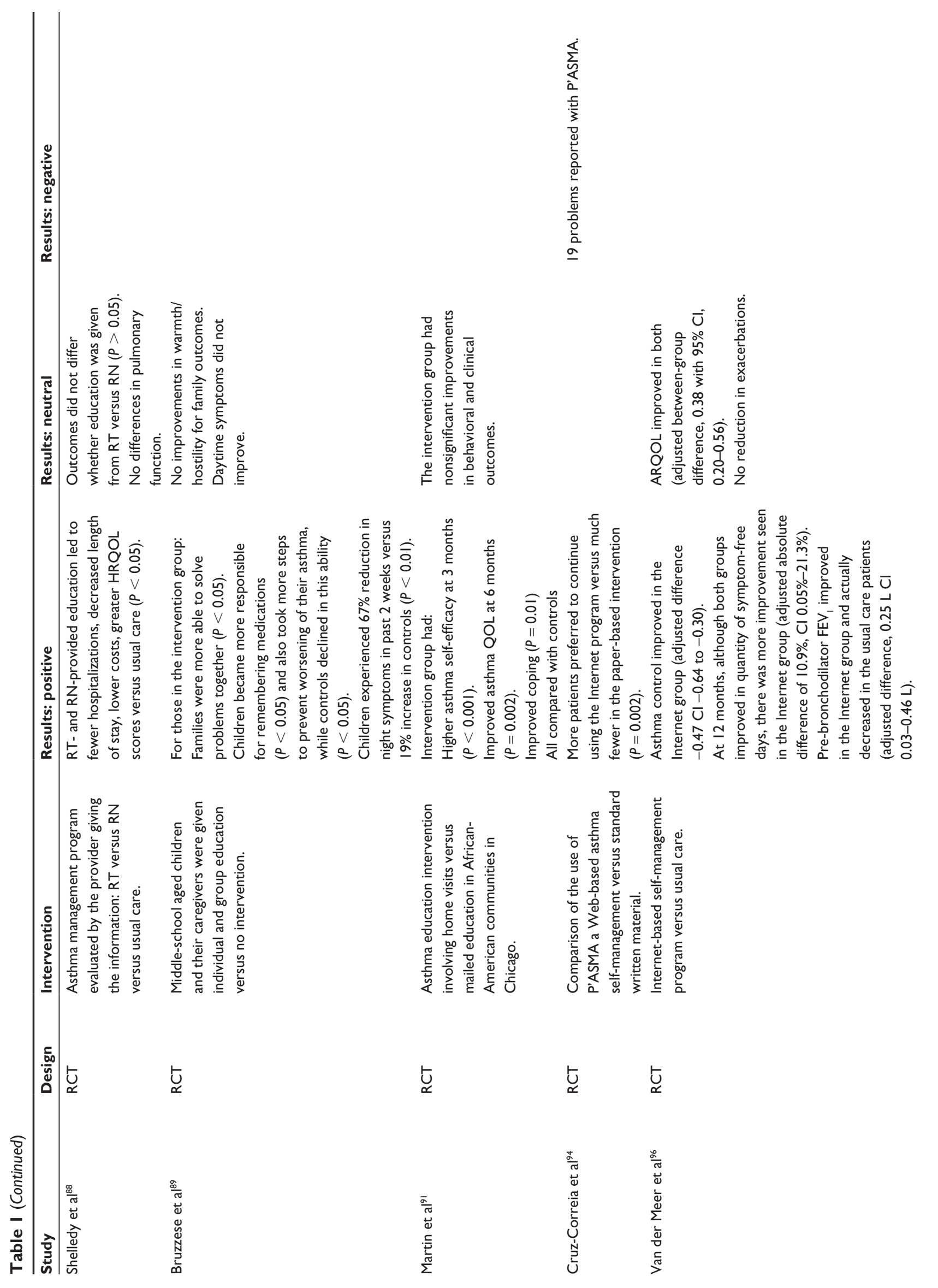



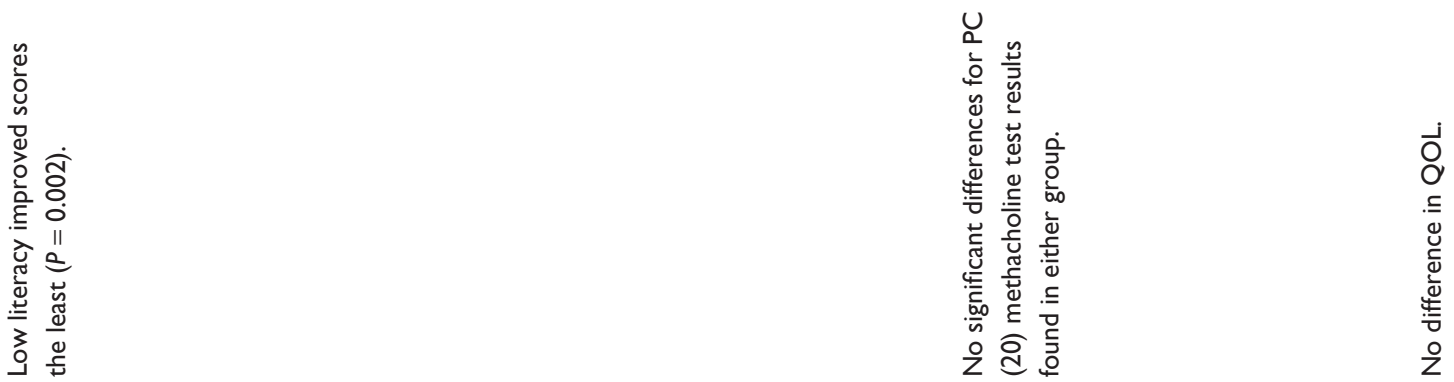

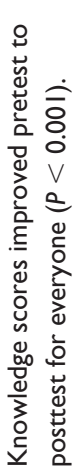
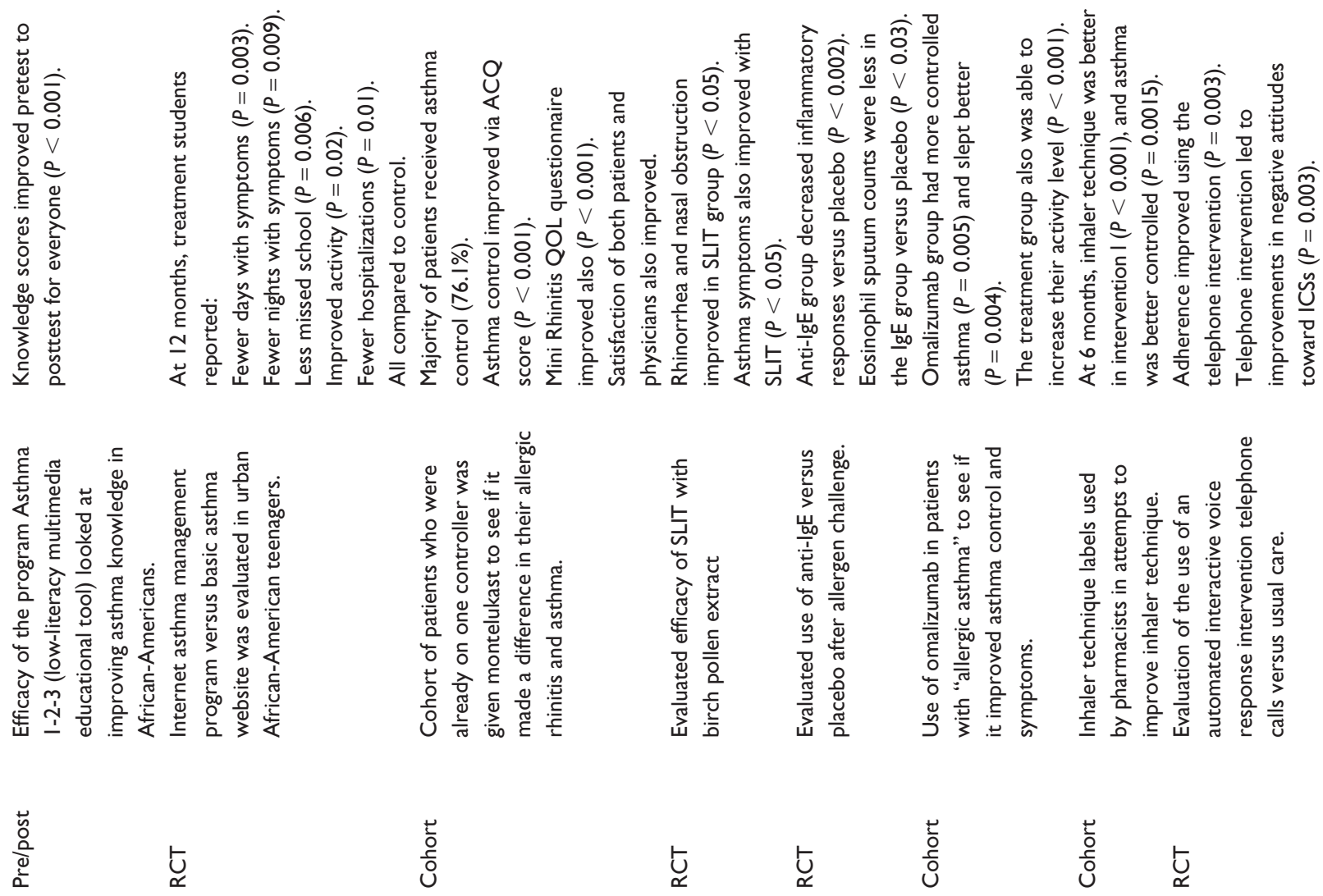

$\frac{\text { ț }}{\stackrel{0}{0}}$

$\begin{array}{lll}\longleftarrow & \longleftarrow & \frac{ \pm}{0}\end{array}$

$\begin{array}{ll}\frac{1}{0} \\ \frac{1}{0} & \cup \\ ن & \end{array}$

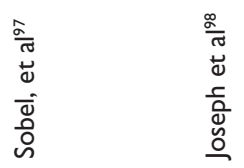

$\frac{1}{\frac{\pi}{0}}$
$\frac{\sqrt{0}}{\frac{5}{0}}$
$\frac{5}{2}$

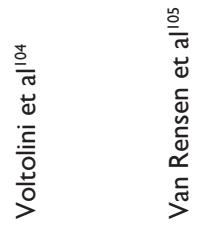

\begin{tabular}{|c|c|}
\hline 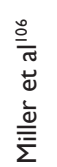 & 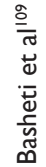 \\
\hline
\end{tabular}




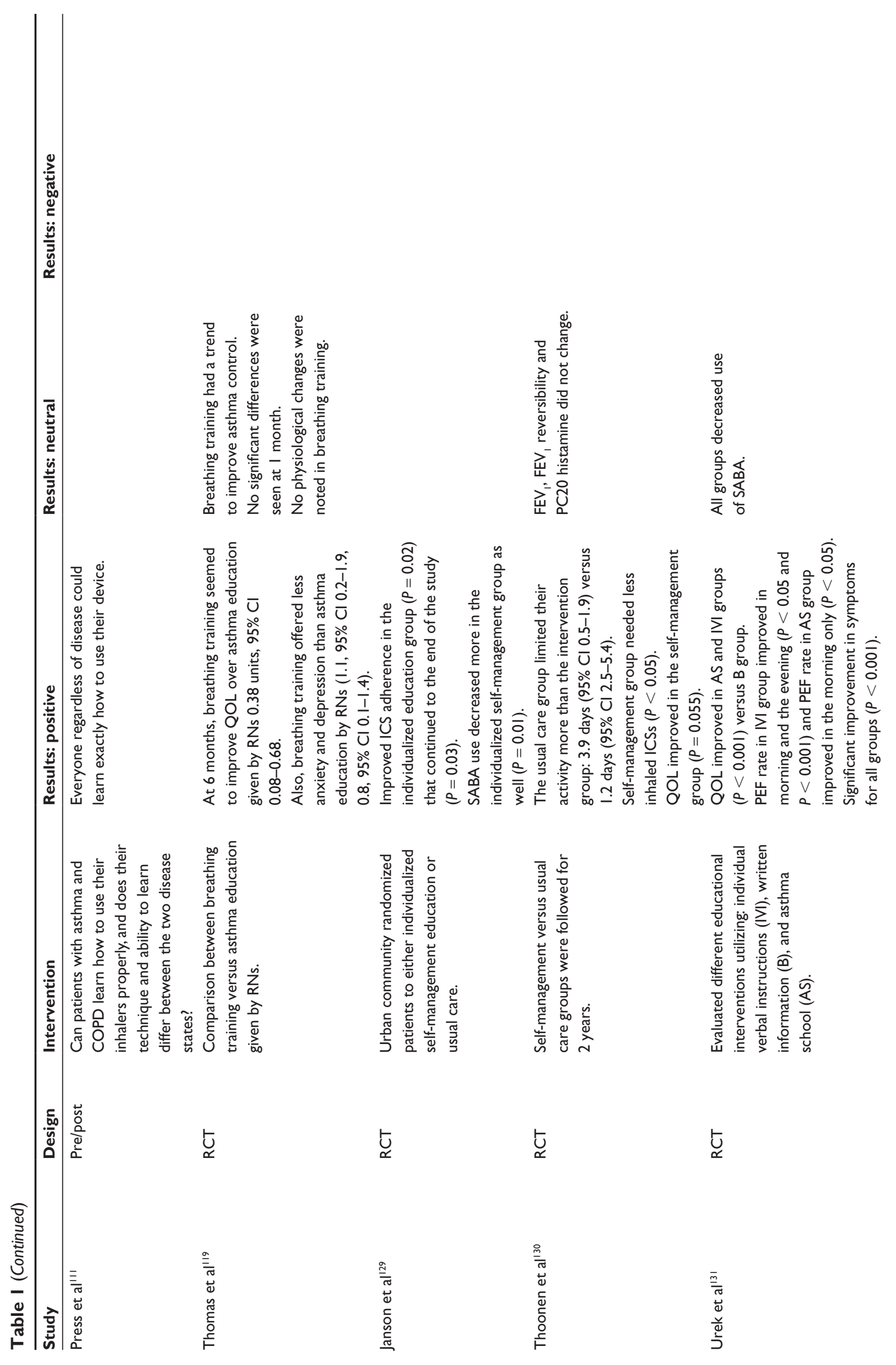



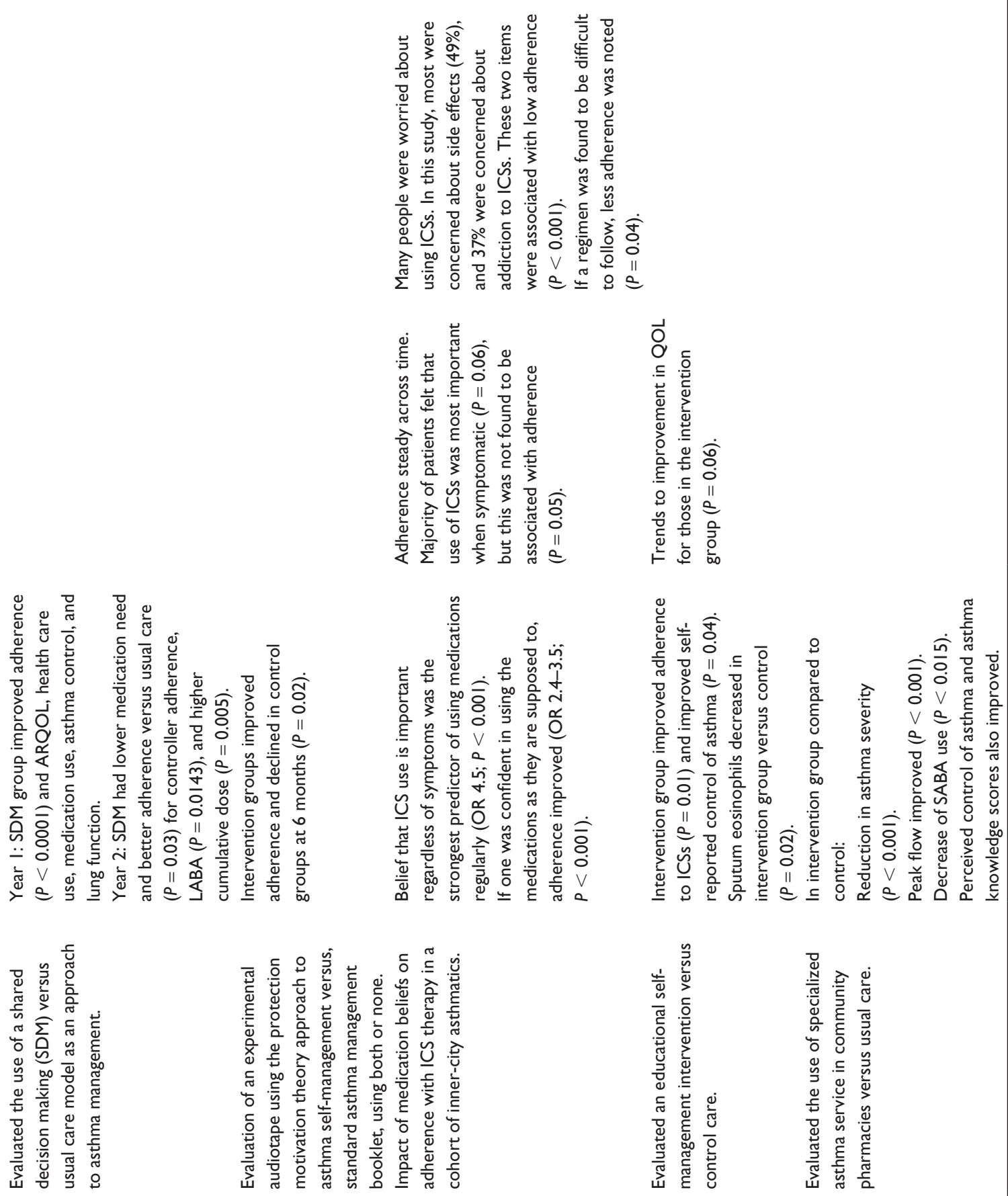

$\underset{\propto}{\longleftarrow}$

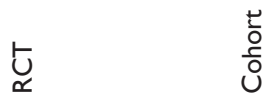

$\underset{\longleftarrow}{\longleftarrow}$

$\underset{\longleftarrow}{\longleftarrow}$

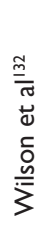

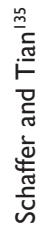

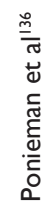

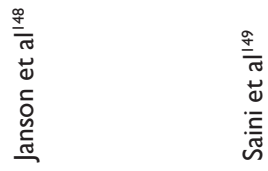




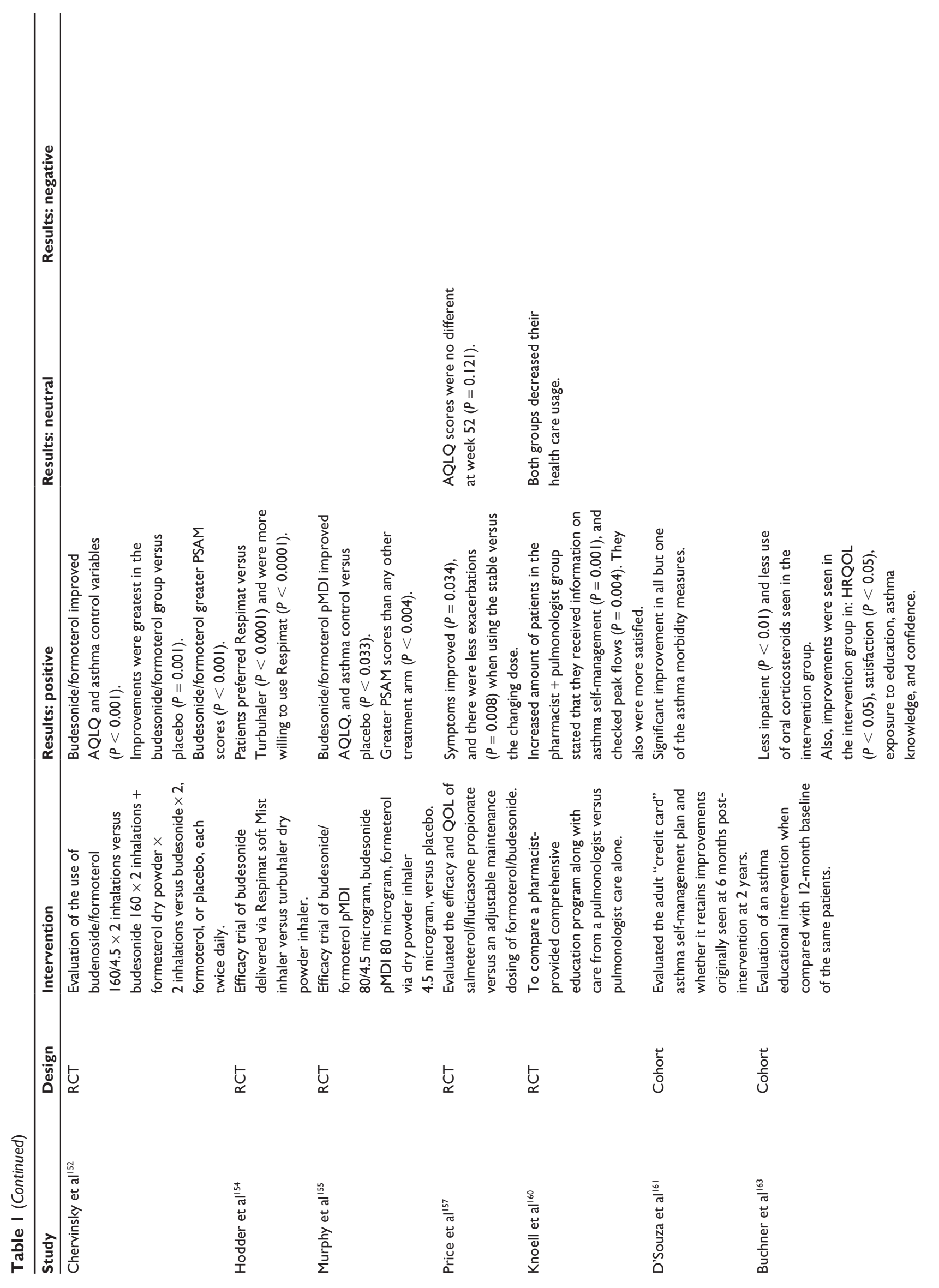



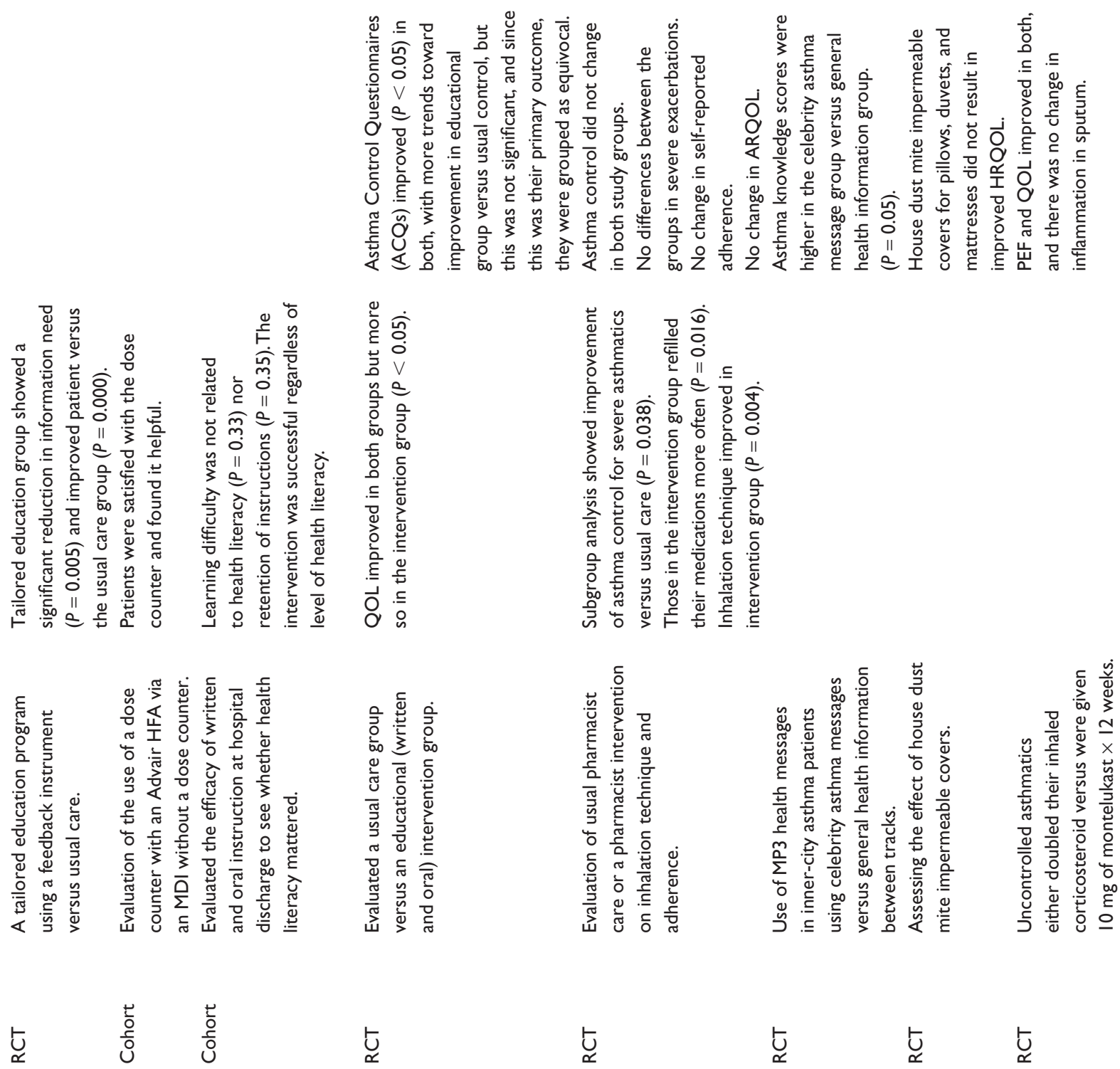

\begin{tabular}{lll}
$\leftarrow$ & $\frac{t}{0}$ & $\frac{t}{0}$ \\
\hdashline & $\frac{0}{0}$ & $\frac{0}{0}$
\end{tabular}

$\underset{\longleftarrow}{\longleftarrow}$

$\underset{\longleftarrow}{\longleftarrow}$

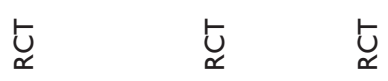

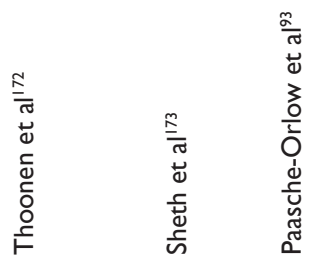
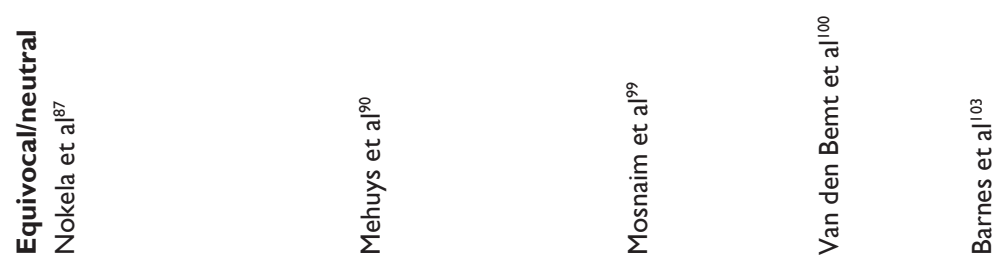


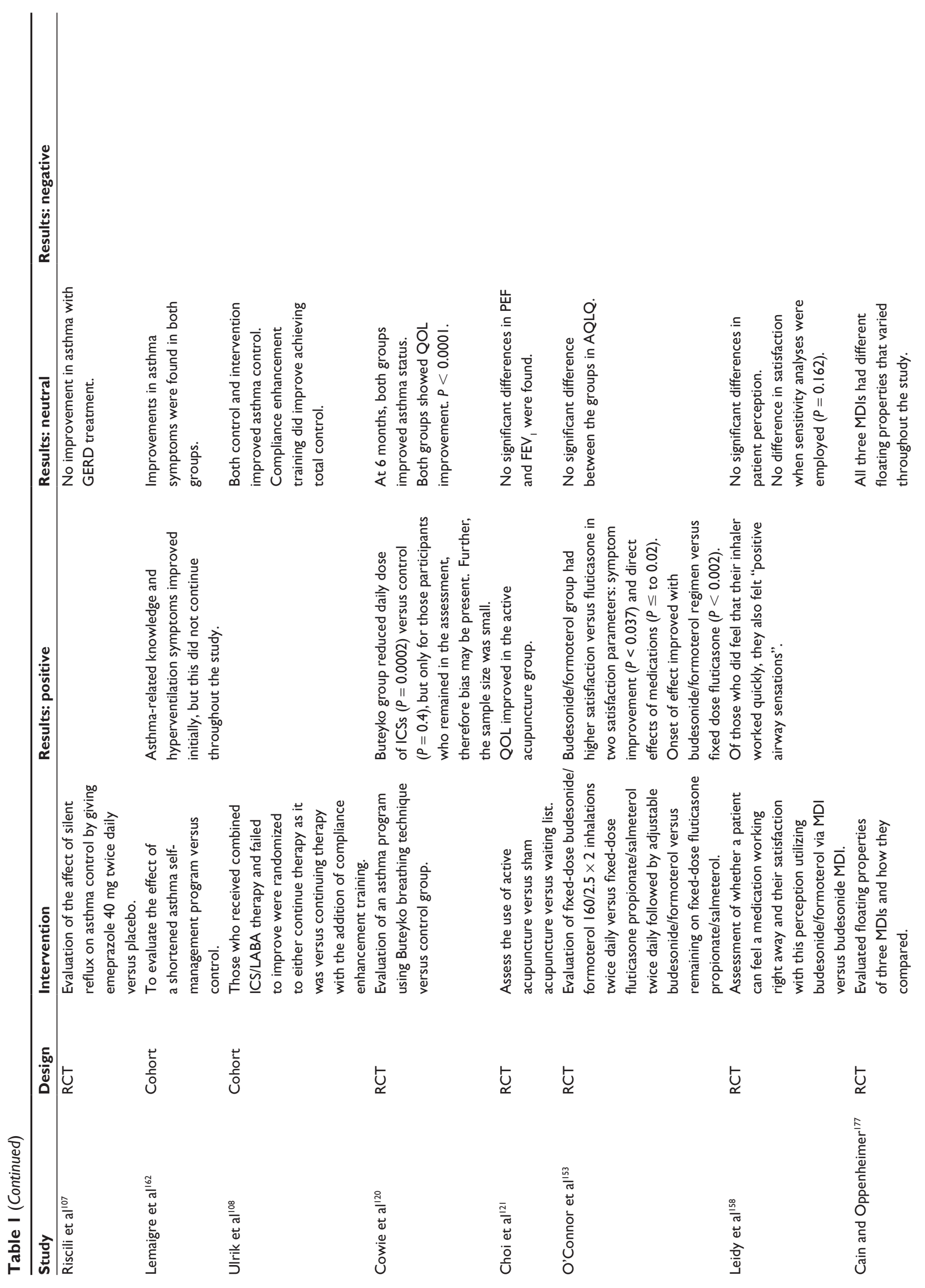




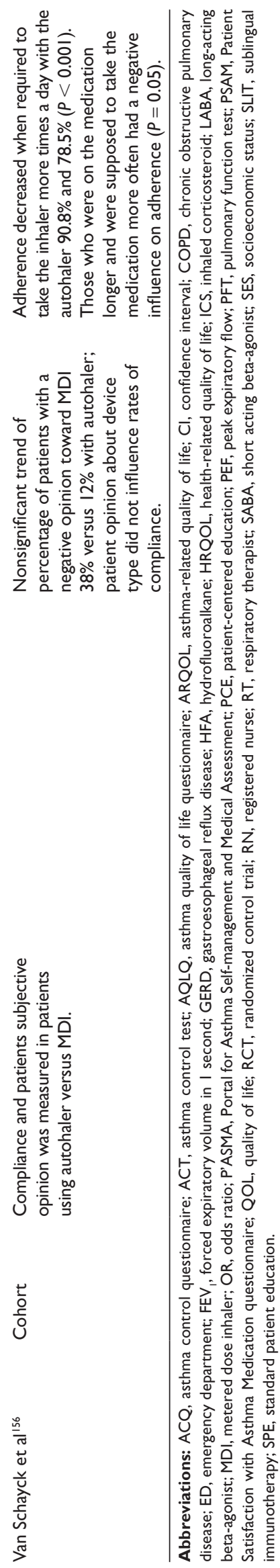

arose was quantifying how patients' perceptions impact asthma control, by looking at patterns of adherence and belief systems. Again, this theme was mostly addressed by descriptive studies (28); though intervention studies found important outcomes with the use of tailored selfmanagement educational programs in patients' perspectives of asthma control, adherence, and beliefs (5:3 positive, 0 neutral, 2 negative).

\section{Adherence and age, personality, and socioeconomic status}

Investigating adherence patterns offers insight into patients' perspectives..$^{30}$ Beginning with adolescence, decisions influencing adherence ${ }^{31,32}$ are often directly related to perceived vulnerability ${ }^{33-36}$ Slack and Brooks, ${ }^{37}$ found that despite positive attitudes toward taking medication for asthma $(P<0.01)$ and considering themselves compliant $(P<0.05)$, adolescents rarely discuss medications with pharmacists, and many wanted more control and additional information. ${ }^{38}$ Similarly, Buston and Wood ${ }^{39}$ showed only $8 \%$ of the adolescents interviewed reported compliance, with the remaining stating that at least one aspect of their treatment plan was forgotten or ignored most of the time. ${ }^{39}$

Adherence to asthma management plans for older adults adds complexity. ${ }^{40}$ Studies have largely excluded this population; additionally Goeman et al acknowledged diagnosing asthma in older adults poses a problem when symptoms are attributed to comorbidities. ${ }^{41}$ Unclear sideeffect profiles (eg, long-acting beta2-agonists), psychosocial factors, costs of medication, and physical limitations all contribute to nonadherence in older adults. Simplification of medication regimens, clearly communicated instructions, with motivational incentives and actively involving patients, may improve adherence to asthma management plans. However, more studies are needed to see whether these interventions would affect adherence and health outcomes.

Additionally, personality traits may relate to adherence. Axelsson et al described the unintentional aspects of personality on adherence and found a significant relationship with negative affectivity and impulsivity on personality test ${ }^{42}$ and poor asthma control in both men and women. ${ }^{7}$ While the day-to-day applicability of this is unclear, personality traits further influence the need for individually tailored therapy plans. ${ }^{43}$ Furthermore, several studies have shown patients who are anxious and depressed have worse asthma control ${ }^{5}$ and quality of life, ${ }^{9}$ in addition to the psychological stressors that impact patients with asthma. ${ }^{4}$ 


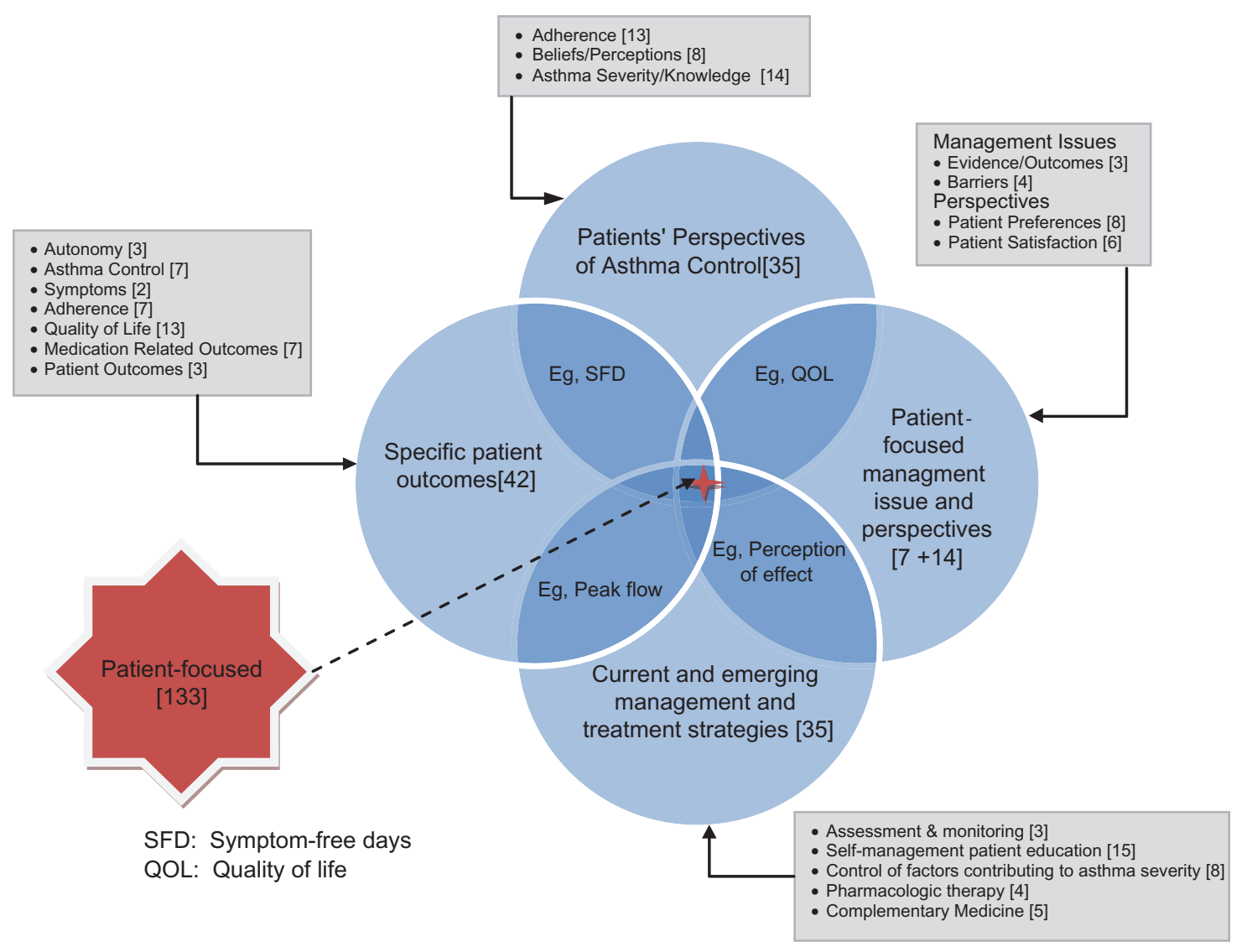

Figure I Themes of results regarding efforts to improve outcomes through patient-focused care in the management of asthma.

Beyond factors such as age and personality, Apter et $\mathrm{al}^{21}$ aimed to identify specific factors that influence asthma severity by studying adherence to twice-daily inhaled corticosteroids (ICSs) and administered surveys to assess patients' understanding and monitoring of their disease. Their study, in fact, demonstrated harm to the patient as adherence to ICSs decreased. Certain factors were associated with decreased adherence such as: less than 12 years of formal education $(P<0.001)$, poor patient-clinician communication $(P<0.001)$, household income less than $\$ 20,000(P=0.002)$, Spanish as primary language $(P=0.005)$, and minority status $(P=0.007)$.

\section{Beliefs and perceptions}

Patients' attitudes toward their disease may influence when and where they seek care. There is ample evidence that many individuals solely seek acute care rather than primary care. ${ }^{44,45}$ Haire-Joshu et al investigated attitudes and knowledge of low-income, African-American adults in an acute-care setting versus an outpatient private specialty clinic. They found the low-income group encountered daily stressors (such as transportation, finances, crime, and occupation) more frequently, and acute-care patients disagreed with the need for routine physician care (21 versus $2 \%$ of private-care patients, $P=0.001)$. They tended to try to "fight asthma attacks" themselves "rather than getting medical help", (75\% versus $49 \%$, $P=0.01)$ and subsequently delayed seeking care (58\% versus $43 \%) .{ }^{46}$ Haire-Joshu et al states that "patient perceptions are important barometers of likely patient action". Likewise, Sibbald $^{47}$ found that asthmatics with greatest morbidity delayed appropriate response to symptoms and that $25 \%$ expressed strong feelings of stigma and pessimism.

Loignon et $\mathrm{al}^{48}$ recognized that patients adapted three different self-care strategies (controlling symptoms, preventing symptoms, or tolerating symptoms), and social factors contribute to which strategy is employed. Putting this idea into action, van der Palen et $\mathrm{al}^{49}$ found that self-management programs influence positive behavioral changes in patients with asthma by randomizing them to an active control group versus a self-treatment group. All patients received self-management training, but the intervention group learned techniques for self-treatment. They found that only the self-treatment group showed improvements in self-efficacy, 
social support, self-treatment and self-management behavior. Identifying how patients' cope with asthma may help clinicians understand how to focus visits.

Adolescent attitudes also lend insight into medication usage patterns. A survey of inner-city high school students evaluated the influence of psychosocial factors on management capabilities: $70 \%$ felt in control of their asthma symptoms, and $63 \%$ had feelings of anxiety. ${ }^{50}$ Those who felt in control of their asthma were more likely to carry their asthma inhaler with them $(\mathrm{r}=72, P=0.004)$. Conversely, those who were embarrassed about their asthma were significantly less likely to do this ( $\mathrm{r}=0.98, P<0.001)$, and only $39 \%$ admitted having asthma to friends. Psychosocial factors can either promote or limit self-management strategies, as adolescents that reported feelings of control over asthma symptoms had more positive attitudes toward selftreatment. ${ }^{50} \mathrm{~A}$ video intervention assessment (VIA) used in adolescents can reveal physical and psychosocial environments and educate clinicians about day-to-day realities of patients. ${ }^{51,52}$

\section{Asthma severity and knowledge}

Patients differ in expectations of asthma management and views of asthma severity when compared with clinicians. ${ }^{27,53,54}$ In a survey of adults with persistent asthma, perceptions of asthma severity and its impact on daily activities found suboptimal control in two-thirds (67\%) and daily symptoms in a quarter $(25 \%)$ of patients. However, daily symptoms did not correlate with reported asthma severity; $37 \%$ of patients with daily symptoms reported their severity as "mild". This disparity was also seen in descriptions of asthma exacerbations; physicians described exacerbations in terms of signs and symptoms, while patients focus on inability to perform activities. Finally, almost half (45\%) of patients did not agree with their doctors' instructions to start controller treatment, indicating that patients' minimize their disease severity. ${ }^{55}$ In another study, patients' perceptions of their ability to influence their asthma symptoms (eg, internal locus of control) related to their level of asthma control. ${ }^{56}$ Choi et al showed that beliefs about disease severity influence asthma medication adherence ${ }^{57}$ and found that beliefs did not differ based on asthma severity or current therapy. Recognizing what patients dislike about their medications gives the physician the opportunity for education as well as intervention to adopt a more inclusive approach when discussing asthma treatment plans. By addressing goals and expectations of asthma management, doctors and patients are more likely to accomplish improved control of asthma.
Further, descriptive studies find the belief that asthma is a periodic instead of a chronic disease infiltrates asthma self-care, but specific interventions focusing on reversing this myth are lacking. One simple question asked by Halm et $\mathrm{al}^{58}$ "Do you think you have asthma all of the time, or only when you are having symptoms?", discovered that half (53\%) believed they only had asthma when they were having symptoms. This belief was associated with a one-third decrease in adherence to ICSs when asymptomatic $(P<0.02)$. This dilemma was echoed by Jones et al study in correlating this belief with poor access to primary care services. ${ }^{59}$ The psychological burden of near-fatal asthma, ${ }^{60}$ along with this dichotomy between symptomatic and preventative treatment of asthma, ${ }^{61,62}$ leads to poor understanding of disease and lack of ability to perceive severity. ${ }^{63}$ Kendrick et $\mathrm{al}^{63}$ investigated 255 patients with asthma from a general practice disease registry in Bristol to see if their perceived view of asthma severity matched peak expiratory flow measurements. Sixty percent of patients were unable to assess their level of asthma control accurately $(P>0.05)$, but the authors also state that although similar findings were previously noted, most were in controlled environments which likely differ from real-life situations. Adherence, whether the provider realizes this or not, is often negatively affected by the patients' perceptions of their symptoms and disease severity. ${ }^{64,65}$ Whether concentrating educational efforts combating this view specifically affect patient outcomes needs to be further investigated.

While most patients value their health care providers' role in decision-making about asthma treatment plans, including patients in treatment decisions is crucial. ${ }^{66}$ Patients desire a larger role, especially when respondents had better insight than clinicians into their own cost barriers and psychosocial factors. Ratcliffe's descriptive study found that all patients wanted their opinions regarding costs related to the visit and how they perceived their symptoms to be heard by their clinicians. ${ }^{67}$ Also, direct patient feedback on corticosteroid use with a physician helps adherence and improves understanding of reasoning why patients stop medications, ${ }^{68}$ providing a framework to tailor specific asthma educational interventions and action plans. ${ }^{58}$ De Vries et al ${ }^{69}$ used a multicenter study to investigate the different variants of an asthma educational program in adults with asthma to see whether patient satisfaction differed with various approaches. They discovered that as the intensity of the educational intervention increased, so did the satisfaction. It becomes clear that patient satisfaction and perspective should be addressed when formulating an asthma treatment plan, and that this needs to occur in conjunction with, instead of "for" the patient. More 
studies will be needed in order to see whether this approach translates into improved patient health outcomes, more than just satisfaction, but collaboration appears to be key in creating coordinated, reliable, and feasible self-management strategies that not only coincide with asthma guidelines but function in the context of patients' lives.

\section{Overview on the current and emerging treatment options for management of asthma}

In this section, we highlight the third theme and provide an overview of current asthma treatment options as described in national and international clinical guidelines and systematic reviews. We also present emerging treatment options with an emphasis on patient-centered care. Of the 35 studies, most were intervention studies (31), of which most had favorable findings (21 positive and 10 equivocal). Studies ranged from 2007-2011 (since guidelines are current through March 2006).

\section{Expert guidelines}

The National Asthma Education and Prevention Program (NAEPP) of the National Heart Lung Blood Institute (NHLBI) aims to "help health care professionals bridge the gap between current knowledge and practice" by convening expert panels to prepare national guidelines (expert panel report, [EPR]) for the diagnosis and management of asthma. ${ }^{70}$ They published three reports, the first in 1991 (EPR $1991)^{71}$ and most recently in 2007 (EPR-3). ${ }^{72}$ This report identified four components of asthma management: assessment and monitoring; patient education; control of factors that may contribute to asthma; and pharmacologic therapy. ${ }^{72}$ Similarly, the Global Initiative for Asthma (GINA) formed in 1993 to disseminate up-to-date information about asthma care, published their first report in $1995 .{ }^{73}$ The most recent 2006 guidelines emphasize the importance of a partnership between patient and caregiver in self-management. ${ }^{74}$

\section{Reviews of asthma management}

Several systematic reviews have evaluated asthma selfmanagement. In our search, we found four reviews in the last decade. Two reviewed management strategies, ${ }^{75,76}$ one evaluated patient-centered approaches, ${ }^{77}$ and the fourth summarized pharmacological strategies for self-management of asthma exacerbations. ${ }^{78}$ When searching for evidence of the four components of asthma management (EPR-3), all four addressed pharmacologic therapies, all but one addressed patient education, but none presented data on assessment and monitoring. Current and emerging therapies highlighted in these reviews are summarized in Table 2.

\section{Current and emerging patient-focused treatment options for asthma}

In this section, we review clinical guidelines and more recent studies updated since their publication, that address patientfocused management of asthma.

\section{Assessment and monitoring}

Guidelines recommend regular ( $\geq$ twice yearly) review of asthma management. The EPR-3 guidelines emphasize elements of assessment and monitoring such as "severity, control and responsiveness to treatment". Standard assessment tools include focused histories and measurements of lung function, such as the examples provided here (Text Box 1).

Because there are multiple barriers to patients receiving regular review of their asthma, patient-centered approaches that decrease these barriers are needed. One novel approach looked at the effectiveness of routine asthma telephone check-ins and showed $26 \%$ more asthma patients' care was reviewed in a practical and cost-effective manner. ${ }^{79}$ Another implemented a computer-generated reminder system to convey education that would encourage self-care ${ }^{80}$ An additional example used an internet program for weekly input by patients, with monitoring and treatment-adjustments by an asthma nurse-specialist. This tailored approach improved asthma control and adherence for the intervention group $(P<0.001$ and $P=0.001$ respectively $){ }^{81}$

\section{Self-management patient education}

High-level evidence exists to support the need to provide asthma self-management education to ensure patients have skills necessary to control their asthma. ${ }^{72}$ This education requires repetition and reinforcement, and the most recent

\begin{tabular}{l} 
Text Box I Assessment and monitoring \\
- Focused history \\
$\circ$ Symptoms \\
$\circ$ Quality of life \\
- Medication review \\
$\circ$ Adherence \\
$\circ$ Side effects \\
$\circ$ Inhaler technique \\
- Lung function (spirometry) \\
$\circ$ Peak flow \\
$\circ$ FEVI \\
$\circ$ Airway responsiveness \\
$\circ$ FeNO \\
\hline
\end{tabular}



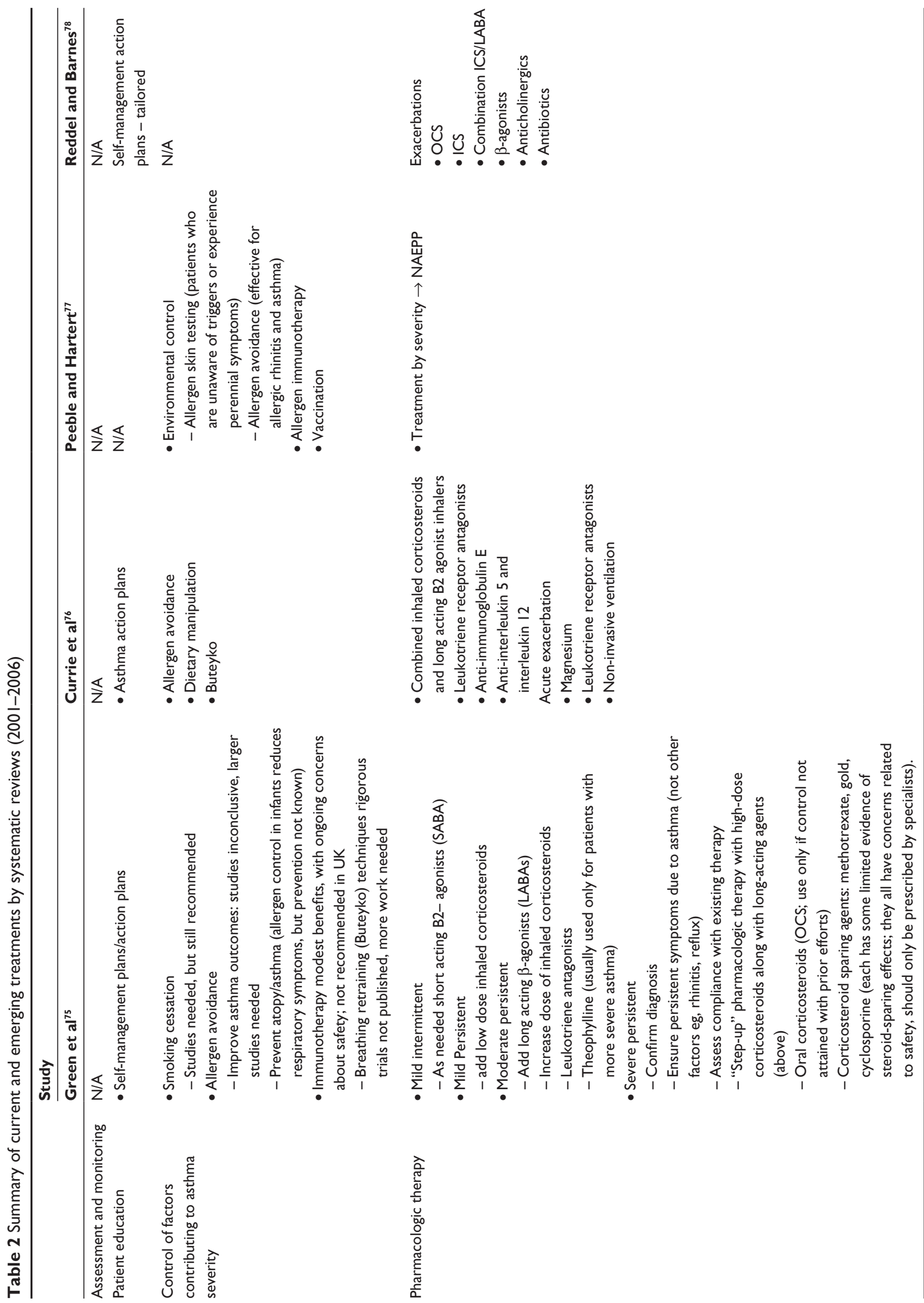

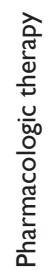




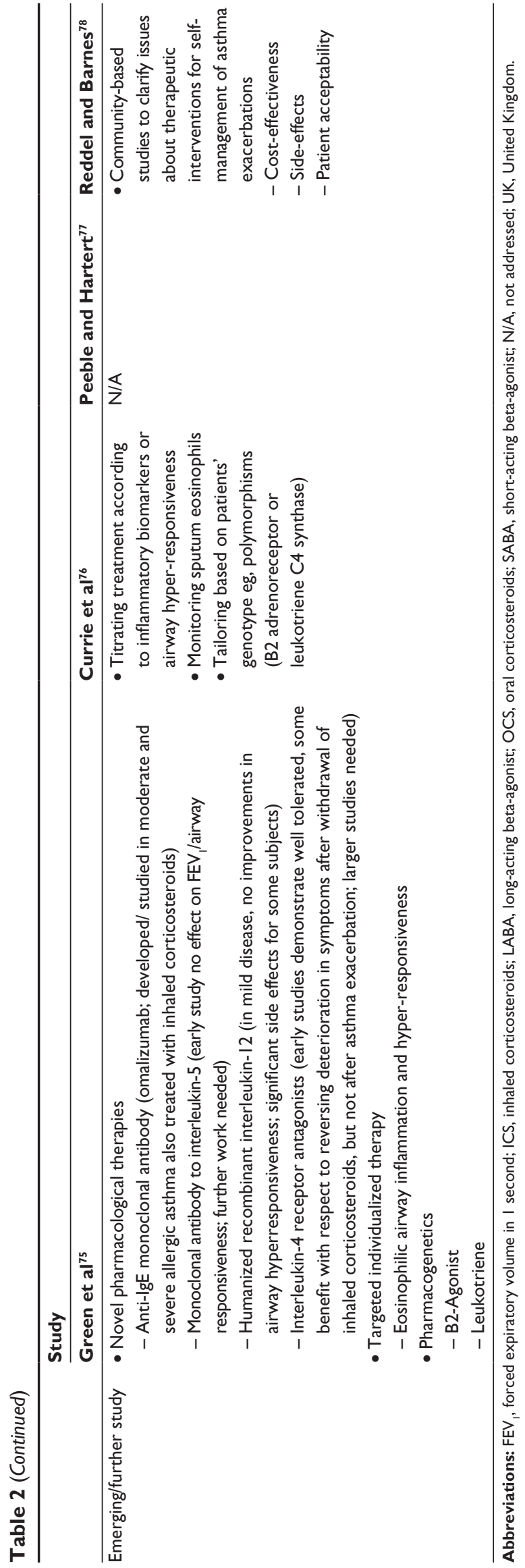

guidelines increased emphasis on written asthma action plans and awareness of cultural and health literacy factors in the delivery of asthma self-management education, ${ }^{72,73}$ such as the items listed here (Text Box 2). Smith et a ${ }^{82}$ noted that until recently, research on asthma education primarily focused on behavior change. They emphasize individual-centered rather than educator-centered education and suggest first identifying and acknowledging patients' individual concerns. ${ }^{71}$

Management programs for asthma may improve patient outcomes while reducing care costs; however, not all are equally effective. Reviews found that the highest level of evidence for success were found with self-monitoring tools (eg, symptom or peak-flow based) coupled with written action plans. ${ }^{72,73,83}$ Newer studies continue to evaluate novel features of various self-management programs. For instance, patient-centered care is now recognized as important in providing high-quality care. Smith et $\mathrm{al}^{84}$ performed a randomized trial evaluating a patient-centered versus standard patient education (SPE) and found subgroups in the intervention group benefited significantly more than the control group. Although this requires further study, patient-centered education may help subpopulations with asthma. Huang et al ${ }^{85}$ evaluated an individualized program for older adults with asthma, and found that indicators of asthma control improved. Tousman et a ${ }^{86}$ developed a "learnercentered" program that utilized homework assignments with "individual status reports" in weekly small group meetings; participants improved in knowledge, quality of life (QOL), and behavior change. Finally, Nokela et a ${ }^{87}$ investigated the use of structured information along with monitoring (asthma diary). Asthma control improved significantly in the intervention group, indicating that a simple patient-driven tool may improve patient outcomes.

\section{Text Box 2 Patient education}

- Regular review of knowledge and control (see text box I)

- Teach at all points of care about*:

- Asthma disease information

- Control

- Symptoms/Triggers

- Roles of medication

- Skill-based self-management

- Encourage partnerships between patients, family and providers - Address concerns/barriers

- Identify preferences

- Develop treatment goals together

- Encourage self-efficacy

*Tailor self-management education on needs and preferences of patient 
Patient education can also occur outside the physician's office. Community settings, including home-based education as studied by Peeble and Hartert et $\mathrm{al}^{77}$ who evaluated the use of respiratory therapists in a home management program, is one example. Also, school-based education programs are frequently used for children; however, Bruzzese et a ${ }^{89}$ noted a paucity of interventions for adolescents with asthma, especially those aged 11-14. They found in their randomized school-based trial that the intervention group had decreased night-time symptoms and improved self-care behaviors. Pharmacists are another way to reach patients outside health care encounters. Mehuys et a ${ }^{90}$ evaluated community pharmacist-led educational interventions and found that they improved adherence and technique with controller medications. One study ${ }^{91}$ strove to improve self-efficacy for African-American adults with asthma through a communitybased intervention with social workers, involving home visits (versus receiving education via mail), and found the intervention group improved self-efficacy, QOL, and coping.

Another important patient-centered issue related to patient education is the concept of health literacy (ability to understand and participate in one's health management). Patients with poor health literacy are at greater risk of worse health outcomes and increased hospitalizations, ${ }^{92}$ and for patients with asthma, this can lead to lack of medication knowledge and inhaler technique. ${ }^{93}$ Written educational materials and self-management tools may themselves be barriers; therefore, use of communication technology, such as web-based technology $y^{94-96}$ and multimedia tools ${ }^{93}$ may be useful in improving knowledge and self-management skills. Cruz-Correia et $\mathrm{al}^{94}$ found that web-based intervention was feasible, safe, and preferred over paper-based formats. Van der Meer et a ${ }^{95,96}$ found patients randomized to an internet-based self-management plus educational intervention versus usual care improved lung function and asthma control, even though exacerbations were unchanged. In African-American patients with low literacy, Sobel et a ${ }^{197}$ found that a multimedia tool significantly improved participants' understanding of asthma, although at higher rates for patients with marginal and adequate literacy versus those with low literacy.

When tailoring self-management education, adolescents may be particularly amenable to technology. One study employed a web-based program targeting urban AfricanAmerican high-school students and found that their tailored approach was not only economical and feasible, but also improved asthma outcomes. ${ }^{98}$ Another used MP3 players to increase knowledge for inner-city African-American adolescents, and found that asthma knowledge improved in those randomized to the intervention group versus control. ${ }^{99}$ Finally, van der Meer et al's internet-based self-management strategy found that adolescents with poor asthma control were more able to incorporate asthma self-management through an internet-based program for a long period of time, while those with good control were not..$^{95}$ This strategy may be particularly useful for this high-risk group of adolescents.

\section{Control of factors contributing to asthma severity}

Despite insufficient evidence that environmental strategies prevent the development of asthma, the guidelines recommend testing for exposure and sensitivity to allergens as well as reduction of allergen and respiratory irritant exposure for management of existing asthma, a brief summary is provided (Text Box 3). Studies continue to evaluate ways to minimize environmental and other triggers. Van den Bemt et al ${ }^{100}$ evaluated the use of dust mite impermeable covers, but did not find improved health-related quality of life (HRQOL) for adults with asthma. In another study, Brodtkorb et al ${ }^{101}$ evaluated the use of laminar airflow during sleep in adolescents with allergic asthma and found that it may add quality-adjusted life-years at a reasonable cost, but further work needs to be done to understand the full potential of this therapy.

Although asthma treatment is the subject of the next section, it is important to highlight that there are some pharmacologic therapies that are being studied to aid in decreasing effect of factors affecting severity of asthma, therefore they will be included here. In one study by Keith et al ${ }^{102}$ montelukast was found to be effective as an add-on therapy for patients with dual diagnoses of asthma and allergic rhinitis, uncontrolled on ICSs or ICSs + longacting beta-agonist (LABA) regimen(s), while another study found improvements in lung function and QOL without modification of effects by decreasing airway inflammation. ${ }^{103}$ Voltolini et al ${ }^{104}$ studied sublingual immunotherapy

Text Box 3 Control of factors contributing to asthma

- Evaluate for allergen exposures

- Test for sensitivity to allergens

- Reduce exposure to allergens

- Avoid exposure to respiratory irritants (eg tobacco smoke)

- Consider allergen immunotherapy for certain individuals

- Evaluate for co-morbid conditions that may interfere with asthma control

- Gastroesophageal reflux disease (GERD)

- Obesity

$\circ$ Rhinitis 
for dual-diagnosed patients, and found promising results in the ability to step down asthma therapy (77\% versus $0 \%$, $P=0.05)$. Van Rensen et $\mathrm{al}^{105}$ found the benefits of omalizumab (anti-IgE) in asthma may be due to a decrease in eosinophilic inflammation. Miller et al ${ }^{106}$ then compared the ability to sleep, work, and participate in activities among patients with IgE-mediated (allergic) asthma. They received salmeterol/ fluticasone combination with or without omalizumab, and found the omalizumab group was more than twice as likely to have controlled asthma (odds ratio $2.62 ; P=0.005$ ). These findings support the use of omalizumab as adjunctive therapy for patients with IgE-mediated (allergic) asthma and who have severe persistent asthma. Riscili et al, ${ }^{107}$ however, did not find empiric treatment of "silent" reflux helpful.

\section{Pharmacologic therapy}

The guidelines provide up-to-date pharmacologic therapy recommendations, such as those listed here (Text Box 4). This section, therefore, will focus on patient-centered approaches to therapeutic advances, including use of respiratory inhalers and complementary and alternative medicine (CAM).

\section{Respiratory inhalers}

Because most asthma medications are delivered by respiratory inhaler devices, adherence to therapeutic regimens is complex, beyond the usual adherence challenges of motivation. Even with good intentions, if patients misuse inhalers, they may not receive an adequate dose, unknowingly decreasing adherence.

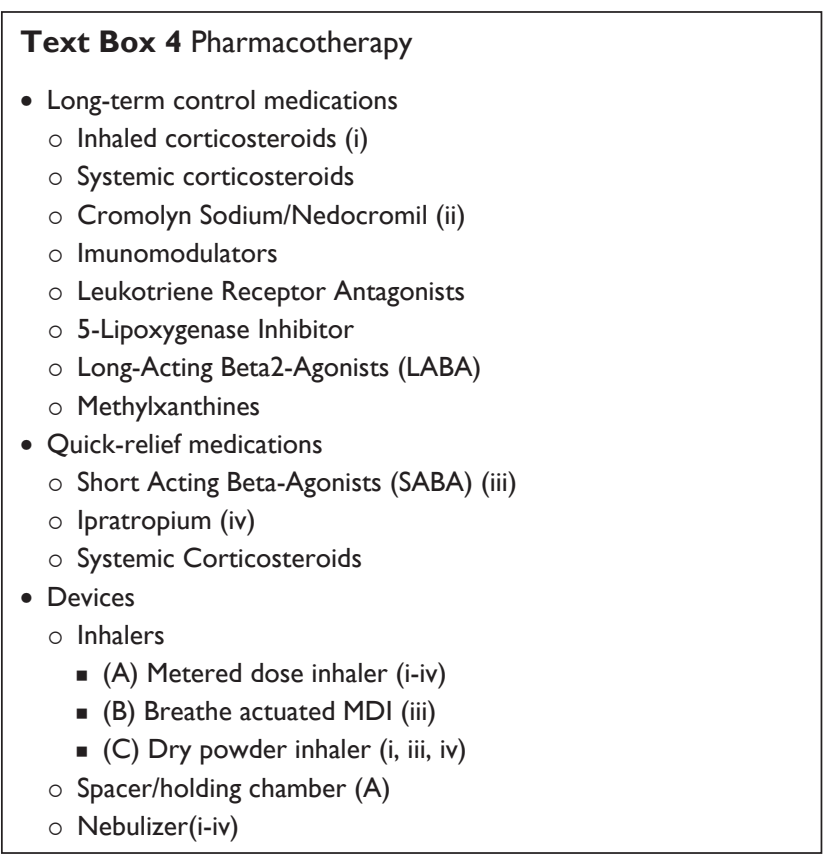

Numerous studies evaluate ability of patients to use inhalers and their preferences and several novel educational strategies aimed to improve skills related to use of medications. Ulrik et $\mathrm{al}^{108}$ evaluated the use of asthma compliance enhancement training with the use of combination salmeterol/fluticasone propionate. This technique did not increase the likelihood of "total control". Another study utilized reminder labels applied directly to inhaler devices to remind patients of inhaler technique after education by pharmacists; this improved technique and asthma outcomes. ${ }^{109}$ One study evaluated an interactive voice response intervention to improve adherence, and found the intervention group adhered 32\% more frequently $(P=0.003) .{ }^{110}$ Paasche-Orlow et a ${ }^{93}$ looked at whether health literacy affected patients' abilities to learn and retain discharge instructions. Although baseline medication knowledge and metered-dose inhaler (MDI) technique were worse for patients with inadequate health literacy, patients were able to learn and retain tailored hospital-based education. Building on this work, Press et $\mathrm{al}^{111}$ specifically evaluated a "teach-to-goal" strategy that utilized cycles of assessment and education of patients until they mastered the inhaler technique. By using these cycles of "teach-back" and education, 100\% of patients, regardless of their level of health literacy, mastered the inhaler technique for both MDIs and Diskus devices, after at most two rounds of teaching.

\section{Complementary and alternative health}

CAM is defined as "a group of diverse medical and healthcare systems, practices, and products that are not generally considered to be part of conventional medicine" by the National Center for CAM. ${ }^{112}$ A prior review by Slader et $\mathrm{al}^{113}$ found a wide range of prevalence estimates (4\%-79\%) for CAM use among asthmatics; the most common use being breathing techniques, herbal products, homeopathy, and acupuncture. Use does not differ by race or ethnicity. ${ }^{114}$ Slader's review found that few studies have shown efficacy in asthma, and therefore conclusions are of limited use due to inadequate quality and small sample sizes. ${ }^{113,115-121}$ At least one study reported adverse effects of use of herbal products for asthma management. ${ }^{122}$ Thomas et al evaluated breathing exercises for asthma. While there was some signal that patient-centered outcomes such as QOL, nonpathophysiologic measures were improved, this technique is unlikely to reduce the need for pharmacologic therapies, ${ }^{119}$ though one study found promising results. ${ }^{120}$ The guidelines state that there is insufficient evidence to recommend/not recommend CAM, with two exceptions: acupuncture is contraindicated in the treatment of asthma (a recent study in 2010 
also found no improvement in pulmonary function, though there was a "favorable effect" on QOL), ${ }^{121}$ and certain herbal preparations are cautioned against for risk of potential harm secondary to either interactions with recommended asthma medications and/or they may be irritants. Most importantly, since up to half of patients do not report CAM use to their clinicians, ${ }^{122}$ the guidelines recommend that clinicians specifically inquire about their patients' use of CAM and advise against substituting CAM for their clinicians' recommended treatment plan.

\section{Identification and impact on specific patient outcomes}

The following section expounds on studies specifying patient priorities in asthma care including autonomy, and how they affect asthma control, QOL, and patient outcomes. The fourth theme focused on patient-centered features of asthma management and resulted in 42 studies, half were descriptive (22), and half were interventions (20), with largely favorable results (16 positive, 3 equivocal, 1 negative).

\section{Autonomy}

Autonomy preferences vary among patients with asthma. Gibson et al examined decision-making and information seeking in relation to QOL. ${ }^{123}$ Subjects recruited from pharmacies were compared with patients who were recently hospitalized for acute severe asthma. Both groups had QOL impairment, but this was greatest in the post-hospitalization group $(P<0.05)$, and as severity of the asthma exacerbation increased, the desire to make decisions decreased $(P<0.05)$. Although patients with asthma have strong preferences for joint decision-making, they do not want to be the sole decision-makers during an exacerbation. These findings are similar to those found in developing countries. ${ }^{124}$ Further, Adams et al $^{125}$ also found that physicians' participatory style relates to patients' use of acute health visits and HRQL. Therefore, while autonomy is important when aiming for high self-efficacy, a balance between autonomy and the ability to use joint decision-making needs to be further explored.

\section{Asthma control outcomes}

Asthma control is considered the ultimate outcome for patients with asthma; patients' perspectives and adherence are directly related to this outcome. Holt et al ${ }^{126}$ describes that although the majority (93\%) of patients studied had suboptimally controlled asthma, most (76\%) felt their asthma was well controlled and were satisfied (80\%) with their control.
It has already been established by previous studies that educational programs for asthma patients result in improved control of asthma. ${ }^{127,128}$ To study whether individualized asthma self-management improved markers of asthma control, Janson et al $^{129}$ performed a randomized control trial of individualized education with self-monitoring of symptoms and peak flow versus usual care. Patients in the self-management group maintained consistently higher ICS adherence levels, and had threefold greater odds of higher than $60 \%$ adherence. Thoonen et $\mathrm{al}^{130}$ investigated whether self-management can provide a safe treatment strategy in general practice by randomizing patients to usual care (UC) or self-management (SM), and the SM group showed a mean of $78 \%$ successfully treated weeks per patient compared with $72 \%$ in the UC group $(P=0.003)$. Urek et al ${ }^{131}$ studied the effect of different educational modalities in asthma control, QOL, and knowledge. Adults with moderate persistent asthma on ICSs received either individual verbal instructions (IVI), written information as an "asthma booklet" (B) or integrated asthma classes "asthma school" (AS). AS and IVI groups showed significantly greater improvement in QOL $(P<0.001)$ and asthma-related knowledge $(P<0.001)$ than the B group. The IVI, the most interactive group, produced the best response overall in both parameters of asthma control and QOL. ${ }^{131}$ Similarly, Wilson et $\mathrm{al}^{132}$ examined a shared decision-making model (SDM) and showed that mutual information sharing improved such factors as QOL.

\section{Symptoms}

One important measure of control is symptom burden. Clinical measures of outcome such as $\mathrm{FEV}_{1}$ (forced expiratory volume in 1 second) and peak flow rates tend to be associated with acute episodes of asthma. This concept led to the development of the "symptom free day" (SFD). ${ }^{133}$ However, since SFD assigns equal weights to symptoms which may not be accurate, McKenzie et al used discrete choice methods to study symptom-based outcome measures by assessing preferences of those with moderate to severe asthma. They showed that patients weigh daytime cough and breathlessness higher than other symptoms. Future studies need to explore preference-based weights for asthma symptoms for improved accuracy of the SFD. ${ }^{133}$ Perceptual accuracy and its relation to treatment adherence has not shown a positive correlation thus far, but respiratory function variability (peak flow variability) within individuals has been correlated with increased symptom perception accuracy. ${ }^{134}$ A specific tool, like peak flow, that provides a consistent framework for both patients and physicians to measure symptom severity is necessary. 


\section{Adherence}

Patient characteristics that influence adherence were addressed above. However, adherence is an important measure of asthma control and therefore this element will be addressed in this section. The effects of asthma education on promoting medication adherence were examined by Schaffer and Tian ${ }^{135}$ by randomly assigning patients to receive an experimental audiotape, a standard asthma-management booklet, both, or no intervention. Mean treatment adherence improved from $15 \%$ to $19 \%$ in the intervention groups and declined $22 \%$ in the control group over the course of 6 months, showing that education is a factor in adherence.

Many factors such as beliefs, attitudes, and experiences of patients influence adherence. Self-management necessitates some degree of active participation and motivation on behalf of the patient. ${ }^{123}$ Ponieman et al ${ }^{136}$ evaluated inner-city asthma patients' beliefs about their ICSs and showed these beliefs influenced adherence, further postulating that addressing modifiable beliefs improves adherence. Asthma patients with a high preference for involvement and information had nonadherence to medication and had a higher interest in self-management. ${ }^{137} \mathrm{~A}$ follow-up study found that the patients' perceived burden of illness plays a more important role for education, self-management, and guideline adherence than the actual severity of the disease. ${ }^{138}$

Other factors that affect adherence outcomes with medical regimens include knowledge, attitudes, and selfefficacy. ${ }^{139}$ Menckeberg et al's study ${ }^{140}$ reiterated what was discussed in the adherence section but are more specific to the medication-related outcomes. Patients' perception of necessity and concerns about side-effects along with environmental factors further influence their attitudes and adherence. Osman ${ }^{141}$ discusses how attitudes are affected by friends, family, and media as well as patients' personal experiences with medication characteristics. He proposes that "for most patients attitudes to medication will follow control of symptoms". By focusing on improving patients' control of symptoms and QOL, we will improve their attitude towards using medication.

\section{Quality of life related outcomes}

Psychosocial factors can also influence patient outcomes. Depressive symptoms and lower degrees of self-efficacy have been correlated with lower asthma-related QOL scores. ${ }^{142-146}$ Calfee et $\mathrm{al}^{147}$ found that greater perceived control was associated with improved physical health status, better asthma-related QOL, fewer days of restricted activity, and lower asthma severity scores. And although these differences were not mediated by changes in asthma practices, there was a significantly decreased prospective risk of ED visits and hospitalizations for asthma which is in contrast to previous studies $^{148,149}$ showing changes as a result of self-management programs. This discrepancy could be linked to inaccurate perceptions of asthma control. Clark et $\mathrm{al}^{7}$ also found that QOL improves in women with asthma when a tailored educational intervention for women was employed. Also, Lloyd et $\mathrm{al}^{150}$ found that people with the worst HRQL were willing to pay the least to avoid symptoms and asthma attacks. Clearly, there is significant influence of psychosocial factors on patient outcomes.

The Asthma Quality of Life Questionnaire (AQLQ) is one method to identify the causes of distress when patients present with acute severe asthma. Adults presenting to the ED with acute severe bronchoconstriction had severe impairment in asthma-specific QOL at baseline, but improved after treatment $(P<0.00001)$. By utilizing tools such as AQLQ, physicians can gain insight into how distressing the experience is for patients, both from a symptomatic and emotional perspective, while identifying the degree and cause of the distress. ${ }^{151}$

\section{Medication-related outcomes}

Current and emerging treatments were discussed above; however, patient outcomes related to use of these therapies will be summarized in this section. Objective measures of improved outcomes such as lung function are commonly used to assess the efficacy of medications. However, these changes may not reflect what patients value, therefore making patient-reported outcomes (PROs) vital to evaluating asthma therapies. Four articles compared PROs between dry powder and pressurized MDIs, ${ }^{153-157}$ and one discussed features of inhaler devices that patients prefer. ${ }^{157}$ Positive correlation to compliance has also been shown with low daily frequency of medication administration. ${ }^{154}$ Patient-reported outcomes addressed were: HRQL ${ }^{155}$ or QOL, ${ }^{139,156}$ ability to sleep, work, and participate in leisurely activities, ${ }^{117,139}$ asthma control, ${ }^{117,139,155,156}$ patient satisfaction, ${ }^{153-157}$ patient preferences, ${ }^{156}$ and onset of effect. ${ }^{156}$ Chervinsky et al, ${ }^{152}$ in a double-blind controlled study of adults with moderate-to-severe asthma, studied PROs on differing doses/combinations of budesonide and/ or formoterol pMDI. They found that the group receiving combined budesonide/formoterol reported significantly greater improvements on the AQLQ(S) and asthma control variables $(P<0.001)$, improved Patient Satisfaction with Asthma Medication Questionnaire scores, and PhysicianPatient Global Assessment. O'Connor et al ${ }^{153}$ looked at the outcome of onset of effect in adjustable versus fixed 
doses of budesonide/formoterol compared with fluticasone/ propionate/salmeterol and found a higher reported onset of effect in the budesonide/formoterol group. Finally, Price et $\mathrm{al}^{157}$ evaluated salmeterol/fluticasone (stable-dose) versus formoterol/budesonide (adjustable maintenance dosing) and found that the former resulted in significant improvements, including increased symptom-free days, decreased rates of exacerbation, and better HRQL.

The question of quick onset of effect of maintenance therapy was addressed by Leidy et al. ${ }^{158}$ They found $87 \%$ who perceived their inhaler working right away identified sensations of easier breathing, and propose if patients feel maintenance therapy works right away, this may provide positive reinforcement and improve adherence. Further studies on this topic are necessary, as perception may be one key to improving adherence. Tying all this together, a study by Schatz et al ${ }^{159}$ looked at the ratio of controller medication to total asthma medication use and its relation to patient-centered outcomes in adult HMO members with persistent asthma. Patients with a ratio of $\geq 0.05$ had mean asthma QOL, asthma control, and symptom severity scale scores that were significantly more favorable $(P<0.0001)$. The authors concluded that the study provided support for the use of the medication ratio as an asthma quality of care measure. ${ }^{160}$

\section{Patient outcomes}

D'Souza et al $^{161}$ evaluated the long-term effectiveness of selfmanagement plans with the adult "credit card". There was a significant improvement in all but one asthma morbidity measure ( $>7$ days out of action). The proportion of "waking most nights" in the previous 12 months decreased from $29 \%$ to $9 \%(P=0.02)$, emergency visits to GPs decreased from $43 \%$ to $16 \%(P=0.001)$, ED visits decreased from $19 \%$ to $5 \%(P=0.02)$, and hospital admissions decreased from $17 \%$ to $5 \%(P=0.04)$. Similarly, Lemaigre et al ${ }^{162}$ showed that even a shortened asthma self-management group program could produce effects on knowledge and asthma symptoms; however, these effects did not persist significantly after 3 months. Lastly, a guideline-based asthma management program within a managed care organization showed statistically significant improvements in patients' HRQL, satisfaction, education, disease knowledge, and confidence in ability to manage their disease. ${ }^{163}$

\section{Patient-focused perspectives}

In this section we review the final theme highlighting patient perspectives on asthma management plans and resulting patient satisfaction. Fourteen studies explored this theme, most (11) were descriptive; of the 3 intervention studies, the findings were mostly in favor of patient-centered care ( 2 positive, 1 equivocal, 0 negative).

\section{Patient preferences}

Ultimately, patient preferences are an important aspect of asthma management. Ulrik et $\mathrm{al}^{164}$ asked patients to rank three treatment models according to preferences: 1) fixed daily-dosing of controller therapy; 2) fixed dosing of controller medication, with written plan outlining adjustment during worsening; 3) or daily-dosing of low-dose combination reliever/controller medication with this inhaler used as needed until control of symptoms occurred. The first model was preferred, and the distribution of preferences mirrored how patients already reported taking their medication. More than half of patients took less medication than prescribed when having fewer symptoms. There was no significant association between self-perceived severity of asthma and the response to therapy in case of exacerbation. These findings illustrate that patients' strategies of management when encountering disease variability are not necessarily driven by their knowledge of disease but more by preferences towards specific strategies. ${ }^{164}$

Another aspect of self-management involves increasing awareness of worsening of disease. Tools to identify patient responses to worsening of their asthma and the reasons for their particular responses need to be improved. While patients prefer monitoring symptoms to peak flow measurements (PFM), likely because of ease ${ }^{161}$ (only 10\%-16\% of patients report use), ${ }^{63,165}$ neither method is perfect. Symptom monitoring lacks objectivity, while peak flow monitoring can be impractical at times. However, preferences for symptom monitoring, despite increased objectivity with $\mathrm{PFM}^{166} \mathrm{dem}-$ onstrates that ease of self-management and simplification of care regimens are patient preferences ${ }^{167}$ of which clinicians need to be aware. Preferences for both education content and modality have also been studied and reveal the Internet and telephone as a preferred means for communication with an information provider. ${ }^{168}$

Incorporating patients' preferences when it comes to treatment decisions has been shown to improve disease management. ${ }^{169}$ McTaggart-Cowan et al ${ }^{170}$ evaluated treatment preferences in terms of risk/benefit tradeoffs using discrete choice experiments and found the relative importance of six attributes of asthma therapy. Patients preferred a treatment regimen that resulted in more SFDs but were willing to forgo some of this benefit in exchange for a more convenient regimen. Furthermore, gender, age, asthma control, and high socioeconomic status were statistically significant predic- 
tors of maintaining current asthma therapy. ${ }^{170}$ This provides useful information for physicians when designing management plans, as every patient has a unique risk-benefit ratio secondary to these factors.

\section{Patient satisfaction}

A tailored approach to management appears to be a key element to patient satisfaction. Studies have examined patient satisfaction from education provided in different settings. ${ }^{67,171}$ In another study performed by Thoonen et al, ${ }^{172}$ patients in a tailored education group had patient satisfaction increase, whereas there was no change in usual care group. Providing patients with tools to evaluate and highlight their own needs and demands was associated with an increase in patient satisfaction. Little et al ${ }^{169}$ found communication aimed at understanding the patients' needs and fears is crucial to patient centeredness. To provide patients with asthma education that they perceive as being relevant to themselves, we have to make our educational interventions both accessible and in accordance to their needs. Preferences for different styles to asthma education according to extent of teaching and intensity showed a significant positive linear association between intensity of the education program and effect on asthma knowledge and HRQL. ${ }^{69}$

This same idea can be applied to specific medication devices; this resulted in one study that examined patient preference for a dose-counter. ${ }^{173}$ Although patients must keep track of doses to determine when to replace their MDIs, ${ }^{173} 63 \%$ do not realize that they are supposed to keep track of the number of actuations, ${ }^{174}$ and $54 \%$ of patients do not know the number of actuations for their inhalers. ${ }^{175}$ Patients use various inaccurate methods to determine MDI depletion, ${ }^{176,177}$ and may then provide "doses" that contain less therapeutic medication. ${ }^{178}$ Patients using their MDIs past the recommended number of actuations compromise their disease control. ${ }^{179}$ Sheth et al ${ }^{173}$ found that $95 \%$ of patients were satisfied with the counter, $92 \%$ agreed that it would prevent them from running out of medication, 73\% felt the MDI dose-counter would help improve control of their disease, and $92 \%$ felt added reassurance about medication supply. By focusing efforts on innovations that make the use of medications easier, the authors propose we can potentially improve efficacy of and adherence to those treatments and consequently asthma control.

\section{Conclusion}

Our review aimed to answer whether patient-centered care improves patient-focused outcomes for patients with asthma. We hypothesized that in order to achieve improved patient outcomes, it is vital to incorporate a patient-centered approach to asthma management, and that clinicians' should expand from managing the disease according to guidelines, to collaborating with patients to self-manage their disease. Our review cited 133 total articles addressing this issue with the majority (43/60) of the intervention studies favoring a patient-centered approach. Many of these studies were in specific patient populations, making these data difficult to generalize, and the interventions themselves may be difficult to implement globally. Therefore, to better answer this question, improved research strategies that incorporate patient-centered techniques will need to be conducted, along with increasing clinician awareness and policy changes.

Current barriers to self-management of asthma can be addressed by patient-centered care, and through novel approaches, we can provide education and expand multimedia tools that better tailor treatment to include psychosocial factors. In addition to patient education, approaches to monitoring, such as checking in via telephone, help to provide patient-focused care in a practical and cost-effective manner.

Providers may perceive their own barriers clashing with the ideals of patient-focused care, such as time limitations and adaptations; however, Clark et al ${ }^{180}$ proved that patientcentered care is a learned skill and can be provided without requiring greater time spent with the patient. While these studies are promising, they alone will not change the type of care patients receive without greater efforts to implement those changes. Further, benefit to the provider as far as improved satisfaction and decreased malpractice has been found. ${ }^{1,2}$

Future patient-centered research studies should investigate feasibility and strategies to implement patient-centered care for a host of patient needs, and should themselves be patient-focused. Without incorporating our patients' viewpoints and insight into treatment plans, suboptimal adherence and patient outcomes are likely.

\section{Acknowledgments}

We would like to thank Meryl Prochaska, Krista Hoff, and Nicole Babuskow for their essential help with this project.

\section{Disclosure}

The authors report no conflicts of interest with this work. Dr Press reports receiving funding from the National Cancer Institute (KM1CA156717). Drs Qamar, Pappalardo, and Arora do not have funding to report. 


\section{References}

1. Irwin RS, Richardson ND. Patient-focused care: using the right tools. Chest. 2006;130(1 Suppl):73S-82S.

2. Bauman AE, Fardy JH, Harris PG. Getting it right: why bother with patient-centered care? Med J Aust. 2003;179(5):253-256.

3. Sexton DL, Stephanie RN, Calcasola SL, Bottomley SR, Funk M. Adults' experience with asthma and their reported uncertainty and coping strategies. Clin Nurse Spec. 1999;13(1):8-14.

4. Vamos M, Kolbe J. Psychological factors in severe chronic asthma. Aust N Z J Psychiatry. 1999;33(4):538-544.

5. Di Marco F, Verga M, Santus P, et al. Close correlation between anxiety, depression, and asthma control. Respir Med. 2010;104(1):22-28.

6. Rhee H, Belyea MJ, Ciurzynski S, Brasch J. Barriers to asthma selfmanagement in adolescents: Relationships to psychosocial factors. Pediatr Pulmonol. 2009;44(2):183-191.

7. Clark NM, Gong ZM, Wang SJ, Valerio MA, Bria WF, Johnson TR. From the female perspective: Long-term effects on quality of life of a program for women with asthma. Gend Med. 2010;7(2): 125-136.

8. Barner JC, Mason HL, Murray MD. Assessment of asthma patients' willingness to pay for and give time to an asthma self-management program. Clin Ther. 1999;21(5):878-894.

9. Kullowatz A, Kanniess F, Dahme B, Magnussen H, Ritz T. Association of depression and anxiety with health care use and quality of life in asthma patients. Respir Med. 2007;101(3):638-644.

10. Bodenheimer T, Edward W, Crumbach K. Improving primary care for patients with chronic illness. The Chronic Care Model, Part 2. JAMA. 2002;288:1909-1914.

11. Kinsman D, Blaser J. Joint principles of a patient-centered medical home released by organizations representing more than 300,000 physicians: principles call for changes at the physician practice level to improve outcomes. ACP Newsroom. Published March 5, 2007. Available from: http:// www.acponline.org/pressroom/pcmh.htm. Accessed March 21, 2011.

12. Mulcahy K, Maryniuk M, Peeples M, et al. Diabetes self-management education core outcomes measures. Diabetes Educ. 2003;29(5): 768-770.

13. Adams SG, Smith PK, Allan PF, et al. Systematic review of the chronic care model in chronic obstructive pulmonary disease prevention and management. Arch Intern Med. 2007;167(6);551-561.

14. Patient Protection and Affordable Care Act 2010. (United States Congress).

15. Little P, Everitt H, Williamson I, et al. Preferences of patients for patient centered approach to consultation in primary care: observational study. BMJ. 2001;322:468-472.

16. Flocke SA, Miller WL, Crabtree BF. Relationships between physician practice style, patient satisfaction, and attributes of primary care. J Fam Pract. 2002;51:835-840.

17. Villanueva AG, Mitchell L, Ponticelli D, et al. Effectiveness of an asthma center in improving care and reducing costs in patients with difficult-to-control asthma. Chest. 2000;118Suppl:815S

18. Laine C, Davidoff F, Lewis CE, et al. Important elements of outpatient care: a comparison of patients' and physicians' opinions. Ann Intern Med. 1996;125:640-645.

19. Koning CJ, Maille AR, Stevens I, et al. Patients' opinions on respiratory care: do doctors fulfill their needs? J Asthma. 1995;32:355-363.

20. White MV, Sander N. Asthma from the perspective of the patient. J Allergy Clin Immunol. 1999;104(2 Pt 2):S47-S52.

21. Apter AJ, Reisine ST, Affleck G, Barrows E, ZuWallack RL. Adherence with twice-daily dosing of inhaled steroids. Socioeconomic and healthbelief differences. Am J Respir Crit Care Med. 1998;157(6 Pt 1): 1810-1817.

22. Barry CA, Bradley CP, Britten N, et al. Patients' unvoiced agendas in general practice consultations: qualitative study. BMJ. 2000;320: 1246-1250.

23. Newcomb PA, McGrath KW, Covington JK, Lazarus SC, Janson SL. Barriers to patient-clinician collaboration in asthma management: the patient experience. J Asthma. 2010;47(2):192-197.
24. Adams SG, Smith PK, Allan PF, Anzueto A, Pugh JA, Cornell JE. Systematic review of the chronic care model in chronic obstructive pulmonary disease prevention and management. Arch Intern Med. 2007;167(6);551-561.

25. Love MM, Mainous AG, Talbert JC, et al. Continuity of care and the physician-patient relationship: the importance of continuity for adult patients with asthma. J Fam Pract. 2000;49:998-1004.

26. Couriel J. Asthma in adolescence. Paediatr Respir Rev. 2003;4(1): 47-54.

27. Price J. The transition of management from childhood to adolescence. Eur Respir Rev. 1997;7:19-23.

28. Lenney W, Wells NEJ, O'Neill BA. Burden of childhood asthma. Eur Respir Rev. 1994;4:49-62.

29. Towns SJ, van Asperen PP. Diagnosis and management of asthma in adolescents. Clin Respir J. 2009;3(2):69-76.

30. Jones KG, Bell J, Fehrenbach C, Pearce L, Grimley D, McCarthy TP. Understanding patient perceptions of asthma: results of the Asthma Control and Expectations (ACE) survey. Int J Clin Pract. 2002;56(2): 89-93.

31. Rhee H, Wyatt TH, Wenzel JA. Adolescents with asthma: learning needs and internet use assessment. Respir Care. 2006;51(12):1441-1449.

32. Jones BL, Kelly KJ. The adolescent with asthma: fostering adherence to optimize therapy. Clin Pharmacol Ther. 2008;84(6):749-753.

33. Marquis P, Trudeau E. Quality of life and patient satisfaction: two important aspects in asthma therapy. Curr Opin Pulm Med. 2001; 7(Suppl 1):S18-S20.

34. Weinstein AG. Direction, motivation, and successful self-management of asthma: focus on drug compliance. J Asthma. 1984;21(4):281-283.

35. Clark N, Jones P, Keller S, et al. Patient factors and compliance with asthma therapy. Respir Med. 1999;93(12):856-862.

36. Ratcliffe J, Van Haselen R, Buxton M, et al. Assessing patients' preferences for characteristics associated with homeopathic and conventional treatment of asthma: a conjoint analysis study. Thorax. 2002;57(6): 503-508.

37. Slack MK, Brooks AJ. Medication management issues for adolescents with asthma. Am J Health-Syst Pharm. 1995;52(13):1417-1421.

38. Reid D, Abramson M, Raven J, et al. Management and treatment perceptions among young adults with asthma in Melbourne: the Australian experience from the European Community Respiratory Health Survey. Respirology. 2000;5(3):281-287.

39. Buston KM, Wood SF. Non-compliance amongst adolescents with asthma: listening to what they tell us about self-management. Fam Pract. 2000;17(2):134-138.

40. Goeman DP, Douglass JA. Optimal management of asthma in elderly patients: strategies to improve adherence to recommended interventions. Drugs Aging. 2007;24(5):381-394.

41. Goeman DP, O'Heir RE, Jenkins C, et al. "You have to learn to live with it": a qualitative and quantitative study of older people with asthma. Clin Resp J. 2007;1(2):99-105.

42. Axelsson M, Emilsson M, Brink E, et al. Personality, adherence, asthma control and health-related quality of life in young adult asthmatics. Respir Med. 2009;103(7):1033-1040.

43. Hyland ME, Ley A, Fisher DW, Woodward V. Measurement of psychological distress in asthma and asthma management programmes Br J Clin Psychol. 1995;34(Pt 4):601-611.

44. Wan T. Use of health services by the elderly in low-income communities. Health Soc. 1982;60(1):82-107.

45. Davis K, Rowland D. Uninsured and underserved: Inequities in health care in the United States. Milbank Q. 1983;61:140-176.

46. Haire-Joshu D, Fisher EB Jr, Munro J, Wedner HJ. A comparison of patient attitudes toward asthma self-management among acute and preventive care settings. J Asthma. 1993;30(5):359-371.

47. Sibbald B. Patient self care in acute asthma. Thorax. 1989;44(2): 97-101.

48. Loignon C, Bedos C, Sevigny R, et al. Understanding the self-care strategies of patients with asthma. Patient Educ Couns. 2009;75(2): 256-262. 
49. Van der Palen J, Klein JJ, Zielhuis GA, van Herwaarden CL, Seydel ER. Behavioural effect of self-treatment guidelines in a self-management program for adults with asthma. Patient Educ Couns. 2001;43(2): 161-169.

50. Cohen R, Franco K, Motlow F, Reznik M, Ozuah PO. Perceptions and attitudes of adolescents with asthma. J Asthma. 2003;40(2): 207-211.

51. Rich M, Lamola S, Amory C, Schneider L. Asthma in life context: Video Intervention/Prevention Assessment (VIA). Pediatrics. 2000;105(3 Pt 1): 469-477.

52. Rich M, Taylor SA, Chalfen R. Illness as a social construct: understanding what asthma means to the patient to better treat the disease. Jt Comm J Qual Improv. 2000;26(5):244-253.

53. Sawyer SM, Fardy HJ. Bridging the gap between doctors' and patients' expectations of asthma management. J Asthma. 2003;40(2):131-138.

54. Nguyen BP, Wilson SR, German DF. Patients' perceptions compared with objective ratings of asthma severity. Ann Allergy Asthma Immunol. 1996;77(3):209-215.

55. Jones A, Pill R, Adams S. Qualitative study of views of health professionals and patients on guided self management plans for asthma. $B M J$. 2000;321(7275):1507-1510.

56. Laforest L, Hasnaoui AE, Pribil C, Riglent C, Schwalm M-S, Ganse EV. Asthma patients' perception of their ability to influence disease control and management. Ann Allergy Asthma Immunol. 2009;102:378-384.

57. Choi TN, Westermann H, Sayles W, Mancuso CA, Charlson ME. Beliefs about asthma medications: patients perceive both benefits and drawbacks. J Asthma. 2008;45(5):409-414.

58. Halm EA, Mora P, Leventhal H. No symptoms, no asthma: the acute episodic disease belief is associated with poor self-management among inner-city adults with persistent asthma. Chest. 2006;129(3): $573-580$.

59. Jones IR, Ahmed N, Kelly M, et al. With an attack I associate it more with going into hospital: understandings of asthma and psychosocial stressors; are they related to use of services? Soc Sci Med. 2008;66(3): 765-775.

60. Vazquez I, Romero-Frais E, Blanco-Aparicio M, et al. Psychological and self-management factors in near-fatal asthma. $J$ Psychosom Res. 2010;68(2):175-181.

61. Hand $\mathrm{CH}$, Bradley $\mathrm{C}$. Health beliefs of adults with asthma: toward an understanding of the difference between symptomatic and preventive use of inhaler treatment. J Asthma. 1996;33(5):331-338.

62. Kaptein AA, Hughes BM, Scharloo M, et al. Illness perceptions about asthma are determinants of outcome. J Asthma. 2008;45(6): 459-464.

63. Kendrick AH, Higgs CM, Whitfield MJ, et al. Accuracy of perception of severity of asthma: patients treated in general practice. $B M J$. 1993;307(6901):422-424.

64. Rubinfeld AR, Pain MCF. Relationship between bronchial reactivity, airway caliber, and the severity of asthma. Am Rev Respir Dis. 1977;115: 381-387.

65. Peiffer C, Marsac J, Lockhart A. Chronobiological study of the relationship between dyspnoea and airway obstruction in symptomatic asthmatic subjects. Clin Sci. 1989;77:237-244.

66. Adams RJ, Smith BJ, Ruffin RE. Patient preferences for autonomy in decision making in asthma management. Thorax. 2001;56(2):126-132.

67. Markson LE, Vollmer WM, Fitterman L, et al. Insight into patient dissatisfaction with asthma treatment. Arch Intern Med. 2001;161(3): 379-384.

68. Onyirimba F, Apter A, Reisine S, et al. Direct clinician-to-patient feedback discussion of inhaled steroid use: its effect on adherence. Ann Allergy Asthma Immunol. 2003;90(4):411-415.

69. De Vries U, Muhlig S, Waldmann HC, et al. Patient satisfaction with different asthma-training variants. Patient Educ Couns. 2008;70(2): 266-275.

70. National Heart Lung and Blood Institute. National Asthma Education and Prevention Program. Available from: http://www.nhlbi.nih.gov/ about/naepp/. Accessed February 11, 2011.
71. Expert panel report: guidelines for the diagnosis and management of asthma (EPR 1991). NIH Publication No. 91-3642. Bethesda, MD: US Department of Health and Human Services; National Institutes of Health; National Heart, Lung, and Blood Institute; National Asthma Education and Prevention Program; 1991.

72. National Heart Lung and Blood Institute. Guidelines for the diagnosis and management of asthma (EPR-3). Available from: http://www.nhlbi. nih.gov/guidelines/asthma. Accessed February 11, 2011.

73. Global Initiative for Asthma [homepage on the Internet]. Available at: http://www.ginasthma.org/ReportItem.asp?intId=96. Accessed April $29,2011$.

74. Global Strategy for Asthma Management and Prevention, Global Initiative for Asthma (GINA); 2008. Available from: http://www.ginasthma.org/ Guidelineitem.asp?|1=2\&|2=1\&intId=1388. Accessed April 29, 2011.

75. Green RH, Brightling CE, Pavord ID, Wardlaw AJ. Management of asthma in adults: current therapy and future directions. Postgrad Med J. 2003;79:259-267.

76. Currie GP, Devereux GS, Lee DKC, Ayeres JG. Recent developments in asthma management. BMJ. 2005;330:585-589.

77. Peeble RS, Hartert TV. Highlights from the Annual Scientific Assembly: patient-centered approaches to asthma management: strategies for treatment and management of asthma. South Med J. 2002;95(7):775-779.

78. Reddel HK, Barnes DJ; for the Exacerbation Advisory Panel. Pharmacological strategies for self-management of asthma exacerbations. Eur Respir J. 2006;28:182-199.

79. Pinnock H, Adlem L, Gaskin S, Harris J, Snellgrove C, Sheikh A. Accessibility, clinical effectiveness, and practice costs of providing a telephone option for routine asthma reviews: phase IV controlled implementation study. Br J Gen Pract. 2007;57:714-722.

80. Curtin K, Hayes BD, Holland CL, Katz LA. Computer-generated intervention for asthma population care management. Eff Clin Pract. 1998;1(1):43-46.

81. Van der Meer V, van Stel HF, Bakker MJ, et al. Weekly self-monitoring and treatment adjustment benefit patients with partly controlled and uncontrolled asthma: an analysis of the SMASHING study. Resp Res. 2010;11:74.

82. Smith S, Mitchell C, Bowler S. Patient-centered education: applying learner-centered concepts to asthma education. J Asthma. 2007;44: 799-804.

83. Gibson PG, Powell H, Wilson A, et al. Self-management education and regular practitioner review for adults with asthma. Cochrane Database Syst Rev. 2003;(1):CD001117.

84. Smith S, Mitchell C, Bowler S. Standard versus patient-centred asthma education in the emergency department: a randomized study. Eur Respir J. 2008;31:990-997.

85. Huang TT, Li YT, Wang CH. Individualized programme to promote self-care among older adults with asthma: randomized controlled trial. $J$ Adv Nursing. 2008;52(20):348-358.

86. Tousman S, Zeitz H, Taylor LD, Bristol C. Development, implementation and evaluation of a new adult asthma self-management program. J Community Health Nurs. 2007;24(4):237-251.

87. Nokela M, Arnlind MH, Ehrs PO, et al. The influence of structured information and monitoring on the outcome of asthma treatment in primary care: a cluster randomized study. Respiration. 2010;79(5): 388-394.

88. Shelledy DC, Legrand TS, Gardners DD, Peters JI. A randomized, controlled study to evaluate the role of an in-home asthma disease management program provided by respiratory therapists in improving outcomes and reducing the cost of care. J Asthma. 2009;46: 194-201.

89. Bruzzese JM, Unikel L, Gallagher R, Evans D, Colland V. Feasiblity and impact of a school-based intervention for families of urban adolescents with asthma: results from a randomized pilot trial. Fam Proc. 2008;47:95-113.

90. Mehuys E, Van Bortel L, De Bolle L, et al. Effectiveness of pharmacist intervention for asthma control improvement. Eur Respi J. 2008;31(4): 790-799. 
91. Martin MA, Catrambone CD, Kee RA, et al. Improving asthma selfefficacy: developing and testing a pilot community-based asthma intervention for African American adults. J Allergy Clin Immunol. 2009;123(1):153-159.

92. US Department of Health and Human Services. Healthy People 2010: Understanding and Improving Health. 2nd ed. Washington, DC: Government Printing Office; 2000.

93. Paasche-Orlow MK, Riekert KA, Bilderback A, et al. Tailored education may reduce health literacy disparities in asthma self-management Am J Respir Crit Care Med. 2005;172:980-986.

94. Cruz-Correia R, Fonseca J, Lima L, et al. Web-based or paper-based self-management tools for Asthma - patients' opinions and quality of data in a randomized crossover study. Stud Health Technol Inform. 2007;127:178-189.

95. Van der Meer V, van Stel HF, Detmar SB, Otten W, Sterk PJ, Sont JK. Internet-based self-management offers an opportunity to achieve better asthma control in adolescents. Chest. 2007;132:112-119.

96. Van der Meer V, Bakker MJ, van den Hout WB, et al. Internet-based self-management plus education compared with usual care in asthma Ann Intern Med. 2009;151:110-120.

97. Sobel RM, Paasche-Orlow MK, Waite KR, Rittner SS, Wilson EAH, Wolf MS. Asthma 1-2-3: a low literacy multimedia tool to educate African American adults about asthma. J Community Health. 2009;34:321-327.

98. Joseph CLM, Peterson E, Havstad S, et al. A Web-based, tailored asthma management program for urban African-American high school students. Am J Respir Crit Care Med. 2007;175:888-895.

99. Mosnaim GS, Cohen MS, Rhoads CH, Rittner SS, Powell LH. Use of MP3 players to increase asthma knowledge in inner-city AfricanAmerican adolescents. Int J Behav Med. 2008;15:341-346.

100. Van den Bemt L, de Vries MP, Cloosterman S, et al. Influence of house dust mite impermeable covers on health-related quality of life of adult patients with asthma: results of a randomized clinical trial. J Asthma. 2007;44(10):843-848.

101. Brodtkorb TH, Zetterström O, Tinghög G. Cost-effectiveness of clean air administered to the breathing zone in allergic asthma. Clin Resp J. 2010;4(2):104-110

102. Keith PK, Koch C, Djandji M, et al. Montelukast as add-on therapy with inhaled corticosteroids or inhaled corticosteroids and long-acting beta-2-agonists in the management of patients diagnosed with asthma and concurrent allergic rhinitis (the RADAR trial). Can Respir J. 2009;16(Suppl A):17A-24A.

103. Barnes N, Laviolette M, Allen D, et al. Effects of montelukast compared to double dose budesonide on airway inflammation and asthma control. Respir Med. 2008;8:1652-1658.

104. Voltolini S, Troise C, Incorvaia C, et al. Effectiveness of high dose sublingual immunotherapy to induce a stepdown of seasonal asthma: a pilot study. Curr Med Res Opin. 2010;26(1):37-40.

105. Van Rensen EL, Evertse CE, van Schadewijk WA, et al. Eosinophils in bronchial mucosa of asthmatics after allergen challenge: effect of anti-IgE treatment. Allergy. 2009;64(1):72-80.

106. Miller DP, Tom G, Rasouliyan L, Chipps B. Patient-reported outcomes among omalizumab and salmeterol/fluticasone combination therapy patients. J Asthma. 2009;46(2):179-185.

107. Riscili BP, Parsons JP, Mastronarde JG. Treating silent reflux disease does not improve poorly controlled asthma. Clev Clin J Med. 2010; 77(3):155-160.

108. Ulrik CS, Claudius BK, Tamm M, et al. Effect of asthma compliance enhancement training on asthma control in patients on combination therapy with salmeterol/fluticasone propionate: a randomised controlled trial. Clin Resp J. 2009;3(3):161-168.

109. Basheti IA, Armour CL, Bosnic-Anticevich SZ, Reddel HK. Evaluation of a novel educational strategy, including inhaler-based reminder labels, to improve asthma inhaler technique. Patient Educ Couns. 2008;72(1):26-33.

110. Bender BG, Apter A, Bogen DK, et al. Test of an interactive voice response intervention to improve adherence to controller medications in adults with asthma. J Am Board of Family Med. 2010;23(2):159-165.
111. Press VG, Arora VM, Shah LM, et al. Misuse of respiratory inhalers in hospitalized patients with asthma or COPD. J Gen Intern Med. Epub Jan 202011.

112. National Center for Complementary and Alternative Medicine [homepage on the Internet]. Available from: http://nccam.nih.gov. Accessed February 11, 2011.

113. Slader CA, Reddel H, Jenkins CR, Armour CL, Bosnic-Anticevich SZ. Complementary and alternative medicine use in asthma: who is using what? Respiratory. 2006;11:373-387.

114. Marino LA, Shen J. Characteristics of complementary and alternative medicine use among adults with current asthma; 2006. J Asthma. 2010;47:521-525.

115. Holloway EA, Lasserson TJ. Breathing exercise for asthma. Cochrane Database Syst Rev. 2004(1):CD1277.

116. Arnold E, Clark CE, Lasserson TJ, Wu T. Herbal intervention for chronic asthma in adults and children. Cochrane Database Syst Rev. 2008(1):CD05989.

117. McCarney RW, Linde K, Lasserson TJ. Homeopathy for chronic asthma. Cochrane Database Sys Rev. 2004;(1):CD0353.

118. Bielory L, Russin J, Zuckerman GB. Clinical efficacy, mechanism of action, and adverse effects of complementary and alternative therapies for asthma. Allergy Asthma Proc. 2004;25:283-291.

119. Thomas M, McKinley RK, Mellor S, et al. Breathing exercises for asthma: a randomised controlled trial. Thorax. 2009;64:55-61.

120. Cowie RL, Conley DP, Underwood MF, Reader PG. A randomised controlled trial of the Buteyko technique as an adjunct to conventional management of asthma. Respir Med. 2008;102(5): 726-732.

121. Choi JY, Jung HJ, Kim JI, et al. A randomized pilot study of acupuncture as an adjunct therapy in adult asthmatic patients. J Asthma. 2010;47(7):774-780

122. Shaw A, Noble A, Salisbury C, Sharp D, Thompson E, Peters TJ. Predictors of complementary therapy use among asthma patients: results of a primary care survey. Health Soc Care Community. 2008, 16(2):155-164.

123. Gibson PG, Talbot PI, Toneguzzi RC. Self-management, autonomy, and quality of life in asthma. Chest. 1995;107(4):1003-1008.

124. Sidana A, Singh D, Mohan A, Guleria R. Quality of life and autonomy preferences in stable asthmatics: a developing country scenario. Respirology. 2009;14(1):83-89.

125. Adams RJ, Smith BJ, Ruffi RE. Impact of the physician's participatory style in asthma outcomes and patient satisfaction. Ann Allergy Asthma Immunol. 2001;86:263-271.

126. Holt S, Kljakovic M, Reid J; for POMS Steering Committee. Asthma morbidity, control and treatment in New Zealand: results of the Patient Outcomes Management Survey (POMS); 2001. NZ Med J. 2003;116(1174):U436

127. Williams MV, Baker DW, Honig EG, Lee TM, Nowlan A. Inadequate literacy is a barrier to asthma knowledge and self care. Chest. 1998 ; 114:1008-1015.

128. Gibson PG, Henry RL, Vimpani GV, Halliday J. Asthma knowledge, attitudes and quality of life in adolescents. Arch Dis Child. 1995;73:321-326.

129. Janson SL, McGrath KW, Covington JK, Cheng SC, Boushey HA Individualized asthma self-management improves medication adherence and markers of asthma control. J Allergy Clin Immunol. 2009;123(4):840-846.

130. Thoonen BP, Schermer TR, Van Den Boom G, et al. Self-management of asthma in general practice, asthma control and quality of life: a randomized controlled trial. Thorax. 2003;58(1):30-36.

131. Urek MC, Tudoric N, Plavec D, Urek R, Koprivc-Milenovic T, Stojic M. Effect of educational programs on asthma control and quality of life in adult asthma patients. Patient Educ Couns. 2005; 58(1):47-54

132. Wilson SR, Strub P, Buist AS, et al. Shared treatment decision making improves adherence and outcomes in poorly controlled asthma. Am J Respir Crit Care Med. 2010;181(6):566-577. 
133. McKenzie L, Cairns J, Osman L. Symptom-based outcome measures for asthma: the use of discrete choice methods to assess patient preferences. Health Policy. 2001;57(3):193-204.

134. Ohm R, Aaronson LS. Symptom perception and adherence to asthma controller medications. J Nurs Scholarsh. 2006;38(3): 292-297.

135. Schaffer SD, Tian L. Promoting adherence: effects of theory-based asthma education. Clin Nurs Res. 2004;13(1):69-89.

136. Ponieman D, Wisnivesky JP, Leventhal H, Musumeci-Szabo TJ, Halm EA. Impact of positive and negative beliefs about inhaled corticosteroids on adherence in inner-city asthmatic patients. Ann Allergy Asthma Immunol. 2009;103:38-42.

137. Schneider A, Wensing M, Quinzler R, Bieber C, Szecsenyi J. Higher preference for participation in treatment decisions is associated with lower medication adherence in asthma patients. Patient Educ Couns. 2007;67(1-2):57-62.

138. Schneider A, Biessecker K, Quinzler R, et al. Asthma patients with low perceived burden of illness: a challenge for guideline adherence. J Eval Clin Pract. 2007;13(6):846-852.

139. Scherer YK, Bruce S. Knowledge, attitudes, and self-efficacy and compliance with medical regimen, number of emergency department visits, and hospitalizations in adults with asthma. Heart Lung. 2001;30(4):250-257.

140. Menckeberg TT, Bouvy ML, Bracke M, et al. Beliefs about medicines predict refill adherence to inhaled corticosteroids. J Psychosom Res. 2008;64(1):47-54.

141. Osman LM. How do patients' views about medication affect their self-management in asthma? Patient Educ Couns. 1997;32(1 Suppl): S43-S49.

142. Mancuso CA, Rincon M, McCulloch CE, et al. Self-efficacy, depressive symptoms, and patients' expectations predict outcomes in asthma. Med Care. 2001;39:1326-1338.

143. Lavoie KL, Cartier A, Labrecque M, et al. Are psychiatric disorders associated with worse asthma control and quality of life in asthma patients? Respir Med. 2005;99:1249-1257.

144. Goldney RD, Ruffin R, Fisher LJ, et al. Asthma symptoms associated with depression and lower quality of life: a population survey. Med J Aust. 2003;178:437-441.

145. Sández E, Vázquez MI, Romero-Frais E, Blanco-Aparicio M, Otero I, Verea H. Depression, panic-fear, and quality of life in near-fatal asthma patients. J Clin Psychol Med S. 2005;12(2):175-184.

146. Schneider A, Lowe B, Meyer FJ, Biessecker K, Joos S, Szecsenyi J. Depression and panic disorder as predictors of health outcomes for patients with asthma in primary care. Respir Med. 2008;102(3): 359-366.

147. Calfee CS, Katz PP, Yelin EH, Iribarren C, Eisner MD. The influence of perceived control of asthma on health outcomes. Chest. 2006;130(5): 1312-1318.

148. Janson SL, Fahy JV, Covington JK, et al. Effects of individual selfmanagement education on clinical, biological and adherence outcomes in asthma. Am J Med. 2003;115:620-626.

149. Saini B, Krass I, Armour C. Development, implementation, and evaluation of a community pharmacy-based asthma care model. Ann Pharmacother. 2004;8:1954-1960.

150. Lloyd A, Mcintosh E, Williams AE, Kaptein A, Rabe KF. How does patients' quality of life guide their preferences regarding aspects of asthma therapy? A patient-preference study using discrete-choice experiment methodology. The Patient: Patient-Centered Outcomes Research. 2008;1(4):309-316.

151. Juniper EF, Svensson K, Mork AC, Stahl E. Measuring health-related quality of life in adults during an acute asthma exacerbation. Chest. 2004;125(1):93-97.

152. Chervinsky P, Baker J, Bensch G, et al. Patient-reported outcomes in adults with moderate to severe asthma after use of budesonide and formoterol administered via 1 pressurized metered-dose inhaler. Ann Allergy Asthma Immunol. 2008;101(5):463-473.
153. O'Connor RD, Patrick DL, Parasuraman B, Martin P, Goldman M. Comparison of patient-reported outcomes during treatment with adjustable- and fixed-dose budesonide/formoterol pressurized metereddose inhaler versus fixed-dose fluticasone propionate/salmeterol dry powder inhaler in patients with asthma. $J$ Asthma. 2010;47(2): 217-223.

154. Hodder R, Reese PR, Slaton T. Asthma patients prefer Respimat Soft Mist Inhaler to Turbuhaler. Int J Chron Obstruct Pulmon Dis. 2009;4:225-232

155. Murphy K, Nelson H, Parasuraman B, Boggs R, Miller C, O’Dowd L. The effect of budesonide and formoterol in one pressurized metered-dose inhaler on patient-reported outcomes in adults with mild-to-moderate persistent asthma. Curr Med Res Opin. 2008;24(3):879-894.

156. Van Schayck CP, Bijl-Hofland ID, Folgering H, et al. Influence of two different inhalation devices on therapy compliance in asthmatic patients. Scand J Prim Health Care. 2002;20(2):126-128.

157. Price DB, Williams AE, Yoxall S. Salmeterol/fluticasone stable-dose treatment compared with formoterol/budesonide adjustable maintenance dosing: impact on health-related quality of life. Respir Res. 2007;8:46.

158. Leidy NK, Gutierrez B, Lampl K, Uryniak T, O’Brien CD. Can patients with asthma feel inhaler therapy working right away? Two clinical trials testing the effect of timing of assessment on patient perception. J Asthma. 2009;46(10):1006-1012.

159. Schatz M, Zeiger RS, Vollmer WM, et al. The controller-to-total asthma medication ratio is associated with patient-centered as well as utilization outcomes. Chest. 2006;130(1):43-50.

160. Knoell DL, Pierson JF, Marsh CB, Allen JN, Pathak DS. Measurement of outcomes in adults receiving pharmaceutical care in a comprehensive asthma outpatient clinic. Pharmacotherapy. 1998;18(6): 1365-1374.

161. D’Souza WJ, Te Karu H, Fox C, et al. Long-term reduction in asthma morbidity following an asthma self-management programme. Eur Respir J. 1998;11(3):611-616.

162. Lemaigre V, Van den Bergh O, Victoir A, De Peuter S, Verleden GM. Effects of a shortened asthma self-management group program. Acta Clin Belg. 2010;65(1):29-36.

163. Buchner DA, Butt LT, De Stefano A, Edgren B, Suarez A, Evans RM. Effects of an asthma management program on the asthmatic member: patient-centered results of a 2-year study in a managed care organization. Am J Manag Care. 1998;4(9):1288-1297.

164. Ulrik CS, Soes-Petersen U, Backer V, Lange P, Harving H, Plaschke P. Disease variability in asthma: how do the patients respond? - and why? J Asthma. 2008;45(6):507-511.

165. Garrett J, Fenwick JM, Taylor G, Mitchell E, Rea H. Peak expiratory flow meters (PEFMs) - who uses them and how does education affect the pattern of utilization? Aust NZ J Med. 1994;24:521-529.

166. Harver A, Humphries CT, Kotses H. Do asthma patients prefer to monitor symptoms or peak flow? J Asthma. 2009;46(9):940-943.

167. Haughney J, Fletcher M, Wolfe S, Ratcliffe J, Brice R, Partridge MR. Features of asthma management: quantifying the patient perspective. BMC Pulm Med. 2007; 7:16.

168. Bush A, Karagiannis GE, Stamatopoulos VG, Kotis T. Public perception of realtime information services for environmental monitoring and management of asthma. J Telemed Telecare. 2006;12(Suppl 1): 11-13.

169. Little P, Everitt H, Williamson I, et al. Observational study of effect of patient centeredness and positive approach on outcomes of general practice consultations. BMJ. 2001;323:908-911.

170. McTaggart-Cowan HM, Shi P, Fitzgerald JM, et al. An evaluation of patients' willingness to trade symptom-free days for asthma-related treatment risks: a discrete choice experiment. J Asthma. 2008;45(8): 630-638.

171. Liu MY, Jennings JP, Samuelson WM, Sullivan CA, Veltri JC. Asthma patients' satisfaction with the frequency and content of pharmacist counseling. J Am Pharm Assoc (Wash). 1999;39(4):493-498. 
172. Thoonen BP, Schermer TR, Jansen M, et al. Asthma education tailored to individual patient needs can optimise partnerships in asthma selfmanagement. Patient Educ Couns. 2002;47(4):355-360.

173. Sheth K, Wasserman RL, Lincourt WR, Locantore NW, CarranzaRosenzweig J, Crim C. Fluticasone propionate/salmeterol hydrofluoroalkane via metered-dose inhaler with integrated dose counter: Performance and patient satisfaction. Int J Clin Pract. 2006;60(10): 1218-1224.

174. Sander N, Fusco-Walker SJ, Harder JM, Chipps BE. Dose counting and the use of pressurized metered-dose inhalers: running on empty. Ann Allergy Asthma Immunol. 2006;97:34-38.

175. Ogren RA, Baldwin JL, Simon RA. How patients determine when to replace their metered-dose inhalers. Chest. 2002;121:871-876.

176. Rubin BK, Durotoye L. How do patients determine that their metereddose inhaler is empty? Chest. 2004;126:1134-1137.
177. Cain WT, Oppenheimer JJ. The misconception of using floating patterns as an accurate means of measuring the contents of metered-dose inhaler devices. Ann Allergy Asthma Immunol. 2001;87:417-419.

178. Guidance for Industry. Integration of Dose-counting Mechanisms into MDI Drug Products. US Department of Health and Human Services, Food and Drug Administration Center for Drug Evaluation and Research, Division of Pulmonary and Allergy Drug Products. Rockville, Maryland: Guidance for Industry; 2003.

179. Bergner A, Griesner WA 2nd, Bergner RK. Metered-dose inhalers: the specified number of sprays. JAMA. 1993;269:1506.

180. Clark NM, Gong M, Schork MA, et al. Long-term effects of asthma education for physicians on patient satisfaction and use of health services. Eur Respir J. 2000;16:15-21

\section{Publish your work in this journal}

Patient Related Outcome Measures is an international, peer-reviewed, open access journal focusing on treatment outcomes specifically relevant to patients. All aspects of patient care are addressed within the journal and practitioners from all disciplines are invited to submit their work as well as healthcare researchers and patient support groups. Areas covered will

Submit your manuscript here: http://www.dovepress.com/patient-related-outcome-measures-journal include: Quality of life scores; Patient satisfaction audits; Treatment outcomes that focus on the patient; Research into improving patient outcomes; Hypotheses of interventions to improve outcomes; Short communications that illustrate improved outcomes; Case reports or series that show an improved patient experience; Patient journey descriptions or research. 